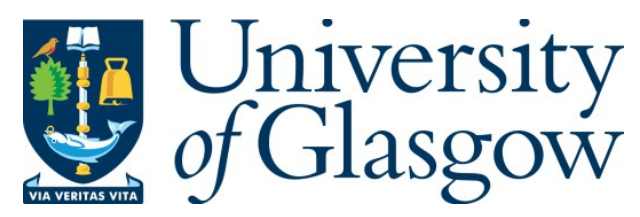

Muthu, M., Yang, E.-H. and Unluer, C. (2021) Resistance of graphene oxide-modified cement pastes to hydrochloric acid attack. Construction and Building Materials, 273, 121990.

(doi: 10.1016/j.conbuildmat.2020.121990)

This is the Author Accepted Manuscript.

There may be differences between this version and the published version. You are advised to consult the publisher's version if you wish to cite from it.

https://eprints.gla.ac.uk/231675/

Deposited on: 18 February 2021

Enlighten - Research publications by members of the University of Glasgow http://eprints.gla.ac.uk 


\section{Resistance of graphene oxide-modified cement pastes to hydrochloric acid attack}

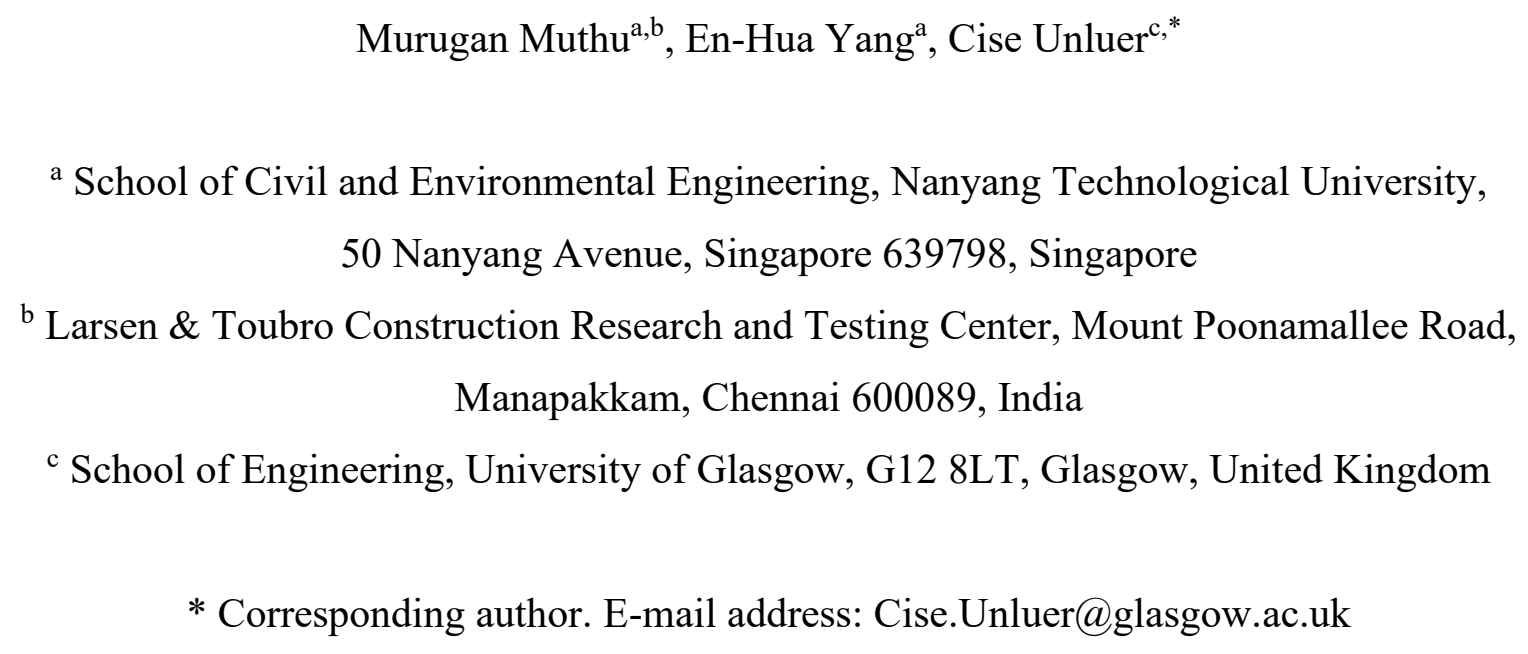
involving up to $0.09 \mathrm{wt}$ \% graphene oxide (GO) under constant exposure to hydrochloric $(\mathrm{HCl})$ acid for four weeks. Samples containing $0.09 \mathrm{wt} . \%$ GO revealed a reduction in mass loss and sectional area loss when compared to the control sample without any GO, highlighting the potential of GO inclusion in improving the resistance of the cement matrix to acid attack. While higher GO dosages reduced the workability and hydration of the fresh paste, the use of GO improved the diffusion resistance of the cement matrix against $\mathrm{HCl}$ exposure by densifying the microstructure. The presence of alumina-silica hydrogel was observed in the altered zones of the acid exposed specimens. While this chemical change occurred in all GO-modified pastes, the micro-hardness of the sample containing $0.09 \mathrm{wt} . \%$ GO was higher than the control sample (i.e. without any GO). The obtained results indicated that the inclusion of up to $0.045 \mathrm{wt} \% \mathrm{GO}$ increased the micro-hardness and reduced the leaching of aluminium and silicon ions, which could effectively prevent the increased formation of microcracks and form a protective barrier against aggressive species in extreme environments.

Keywords: Portland cement; graphene oxide; hydrochloric acid attack; calcium leaching; 33 performance 


\section{INTRODUCTION}

Reinforced concrete is used in the construction of various infrastructures such as chemical warehouses, cooling towers, activated sludge and septic tanks, wastewater clarifiers, and radioactive waste storage structures [1-4]. The concrete used in these structures is often exposed to aggressive chemicals. It is prone to deterioration, which is a combined diffusiondissolution-precipitation process. The hardened cement paste is an assemblage of calcium silicate hydrates, portlandite, ettringite, monosulfate, and unhydrated cement particles. The pore solution of the cement matrix is made up of alkalis $\left(\mathrm{Na}^{+}, \mathrm{K}^{+}\right)$, calcium, and hydroxyl ions. The chemical attack on the concrete first alters the concentration of these ions in the pore solution. Such an ionic imbalance reduces the $\mathrm{pH}$ of concrete, leading to three major issues: (i) cement dissolution, (ii) steel corrosion, and (iii) strength loss [5-8]. In particular, acid attack on the cement matrix results in the leaching of calcium ions from the hydrate phases and unhydrated cement clinker into the external solution $[4,9,10]$. Such deterioration induces volume change in the material, which coarsens the microstructure of concrete and leads to the formation of surface cracks [11].

Acid attack in concrete structures is characterised by the formation of an affected zone surrounding the core cement-based material, which leads to loss of strength and durability [3, $5,12]$. The deterioration mechanism of the cement matrix under organic and mineral (e.g., nitric, sulfuric, carboxylic, hydrochloric, citric, acetic, lactic, propionic, and butyric) acids have been investigated [2, 4, 13]. Some of the most observed deterioration cases involve hydrochloric $(\mathrm{HCl})$ acid attack on concrete exposed to industrial and wastewater environments.

Gutberlet et al. [3] reported the significant precipitation of calcium chloride $\left(\mathrm{CaCl}_{2}\right)$ salt in the affected zone of the cement matrix subjected to $\mathrm{HCl}$ attack. Two forms of $\mathrm{CaCl}_{2}$ salt were precipitated in this deteriorated zone. Accordingly, one of these salts was highly soluble, whereas the other was less soluble under aqueous mediums. The altered area was mainly occupied with the insoluble calcium-based salt and amorphous hydrogel. The reaction between the insoluble metal cations and hydrogels could result in the formation of iron-silica (Fe-Si), alumina-silica (Al-Si), and calcium-alumina-silica (Ca-Al-Si) complexes. At $\mathrm{pH}$ values below 3.5, these metallic compounds could collapse and dissolve into the acidic medium [4, 14-16]. 
When compared to hydrochloric acid $(\mathrm{HCl})$ attack, the degree of crazing was very high in the altered zone of the cement matrix subjected to $\mathrm{HCl}$ attack [3]. The classification of the formation of zones across the cement matrix under $\mathrm{HCl}$ and nitric acid $\left(\mathrm{HNO}_{3}\right)$ attacks revealed the surrounding of the innermost unaltered core by a zone of brown discolouration (ferrous hydroxide) $[3,5,15,16]$. These two zones were encompassed by the outermost milky white precipitates (amorphous alumina-silica hydrogel) that possessed a similar $\mathrm{pH}$ as the acidic medium. In contrast, the $\mathrm{pH}$ in the unaltered zone remained alkaline [12].

One route for reducing damage due to acid attack involves the incorporation of fly ash, metakaolin, and silica fume in the mix design, which can improve resistance against aggressive chemicals. However, the inclusion of these mineral additives in high dosages can reduce the alkalinity of concrete, also posing a durability concern [17, 18]. Alternatively, various nanomaterials (e.g., carbon nanotubes, carbon nanofibers, and oxides of alumina, silica, and titanium) have been used to enhance the performance of concrete against chemical attack [1921]. While potentially effective, the homogenous dispersion of nanoparticles in fresh concrete presents challenges [21].

Graphene oxide (GO) is composed of a single layer of mixed $\mathrm{sp}^{2}$ and $\mathrm{sp}^{3}$ hybridised carbon atoms, functionalised with different oxygen-containing functional groups such as carbonyl, hydroxyl, and carboxyl [22]. GO has a wrinkled sheet-like morphology, and the functional groups are grafted on its basal plane and edges. It is one of the graphene derivatives that is hydrophilic and can be extracted at a low cost on a large scale using Hummers' method [23]. The oxygen-derived functional groups grafted onto the GO edges prevent van der Waals forceinduced agglomeration of GO [24]. As a result, GO can disperse well in the cement matrix and interact electrostatically with the cement clinker [25]. GO could be used as a filler to strengthen the microstructure of concrete operating in industrial conditions because of its high surface area $\left(1500-1700 \mathrm{~m}^{2} / \mathrm{g}\right.$ ), planar structure (size of the single-layer is $0.7-1 \mathrm{~nm}$ thick and $0.1-100$ $\mu \mathrm{m}$ wide), easy dispersion, and excellent mechanical properties (in-plane Young's modulus 210-470 GPa) [22].

Previous studies [26] that examined the hydration kinetics of cement pastes containing up to 0.06 wt. \% GO revealed an increase in the heat flow of these samples with an increase in GO dosage. While another study [27] showed that the inclusion of $0.05 \mathrm{wt} . \%$ GO led to a decline in the workability of cement composites in comparison to control mix (i.e. without any GO), 
the compressive and flexural strengths increased by $24 \%$ and $35 \%$, respectively. The inclusion of GO bridged the pores and cracks, explaining the improvements in the performance of these composites. Qureshi and Panesar [28] reported a reduction in the workability of fresh cement pastes when GO was included in place of pristine graphene. The workability of cement pastes decreased with an increasing GO dosage, which was associated with the consumption of the free water onto GO surfaces, prior to the access of cement particles [29, 30].

Considering these potential benefits, the effects of the incorporation of GO within cement composites subjected to aggressive environments have not been investigated in detail. To fill this gap in the literature, this study aims to evaluate the degradation of GO-modified cement pastes subjected to $\mathrm{HCl}$ attack. The presented work contributes to the development of GOmodified cement composites by examining their deterioration characteristics and microstructural changes in an aggressive chemical environment. To enable a comprehensive analysis, the changes in specimen mass and sectional area over acid exposure time were recorded. The mineralogical, chemical and mechanical changes in the altered zone of GOmodified cement pastes were assessed using X-ray diffraction (XRD), thermogravimetric analysis (TGA), Fourier transform infrared spectroscopy (FT-IR), scanning electron microscopy and energy-dispersive X-ray spectroscopy (SEM-EDS), and Vickers microhardness tests. Changes in the characteristics of $\mathrm{HCl}$ solution due to cement leaching were also monitored using $\mathrm{pH}$ and conductivity meters, and inductively coupled plasma optical emission spectroscopy (ICP-OES). These results were further supported via the evaluation of the impact of GO inclusion on the fresh properties of cement pastes through the assessment of properties such as heat of hydration and rheology. The findings of this study highlighted the suitability of these composites for being used in the construction of critical structures (e.g. chemical storage and wastewater treatment plants).

\section{MATERIALS AND METHODOLOGY}

\subsection{Materials}

In this study, water-soluble GO with a concentration of $4 \mathrm{mg} / \mathrm{mL}$ was obtained from Sigma Aldrich Ltd. (Singapore). This GO, extracted from natural graphite (99\% carbon-based, size $150 \mu \mathrm{m})$, was synthesized using the modified Hummers' method [23, 31]. The details of the 
synthesizing procedure are reported in Ghazizadeh et al. [32]. A sample from this GO was taken, dried in an oven at $80^{\circ} \mathrm{C}$ for 24 hours, washed in acetone, deposited on a filter paper, and finally vacuum desiccated for 7 days. This dried GO sample was characterised by employing X-ray photoelectron spectroscopy (XPS), SEM-EDS, and FT-IR.

In preparation for XPS analysis, the GO sample was pressed onto a carbon substrate, which was covered with indium to avoid the background contribution from the substrate. The sample, together with the substrate, was then mounted into a Kratos Analytical Axis Supra XPS operating with a monochromated $\mathrm{Al} \mathrm{K \alpha}$ source $(\mathrm{E}=1486.6 \mathrm{eV})$. The XPS spectra were collected over a spot size of $400 \mu \mathrm{m}$ and dwell time of 50 milliseconds. The XPS survey was repeated three times with a $1 \mathrm{eV}$ resolution, and the $\mathrm{C} 1 \mathrm{~s}$ spectrum was recorded multiple times with a resolution of $0.1 \mathrm{eV}$. The dried GO flakes were mounted onto a steel stub wrapped with carbon adhesive tape and assessed via SEM operated at a low voltage under the secondary electrons (SE) mode. For FT-IR analysis, the dry GO sample was directly placed under the metal tip of the instrument and scanned at an IR wavelength range of $4000-400 \mathrm{~cm}^{-1}$.

Fig. 1(a) shows the XPS spectrum of the GO sample, also indicating the C1s pattern. The quantification results obtained via XPS are listed in Table 1. The results revealed that the GO sample was highly oxidized, with an oxygen-to-carbon ratio of about 0.5 . Three chemical states of carbon, including $\mathrm{sp}^{2}$ and $\mathrm{sp}^{3}$ hybridised, $\mathrm{C}=\mathrm{O}$ and $\mathrm{C}-\mathrm{O}$, and carboxyl-like structures were observed, which is consistent with the findings of previous studies [22, 33]. Fig. 1(b) shows the morphology and chemical composition of the GO sample. The dried GO sheets were found to be randomly twisted, and their surfaces had a wrinkled morphology. Fig. 1(c) shows the FTIR spectrum of the GO sample, revealing bands at wavelengths of $1735 \mathrm{~cm}^{-1}, 1210 \mathrm{~cm}^{-1}, 1050$ $\mathrm{cm}^{-1}$, and $974 \mathrm{~cm}^{-1}$, which corresponded to $\mathrm{C}=\mathrm{O}, \mathrm{C}-\mathrm{O}-\mathrm{C}, \mathrm{C}-\mathrm{OH}$, and $\mathrm{C}-\mathrm{O}$ functional groups, respectively. This outcome confirmed that the GO sample was highly oxidized and functionalized with oxygen-derived functional groups. 

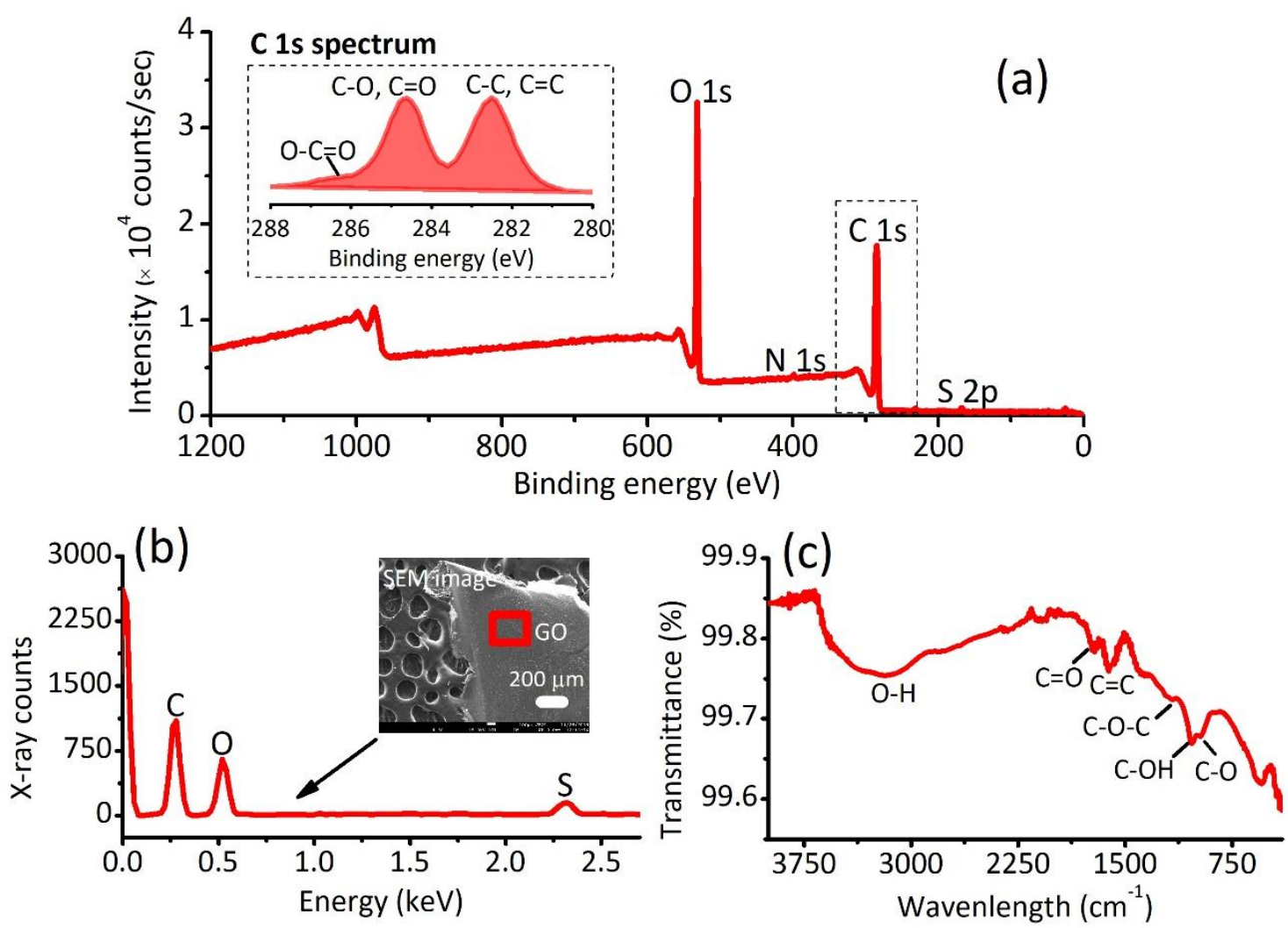

Fig. 1 Characterization of the GO sample via (a) XPS (inset figure showing the C1s spectrum), (b) SEM-EDS and (c) FT-IR

169

\begin{tabular}{cccccc}
\hline Peak & $\begin{array}{c}\text { Binding } \\
\text { energy }(\mathrm{eV})\end{array}$ & $\begin{array}{c}\text { Atomic } \\
\text { conc. }(\%)\end{array}$ & $\begin{array}{c}\text { Error } \\
(\%)\end{array}$ & $\begin{array}{c}\text { Mass } \\
\text { conc. }(\%)\end{array}$ & $\begin{array}{c}\text { Error } \\
(\%)\end{array}$ \\
\hline N 1s & 398 & 0.6 & 0.1 & 0.6 & 0.2 \\
S 2p & 166.4 & 0.6 & 0.03 & 1.4 & 0.1 \\
C 1s & 282.5 & 72.4 & 0.3 & 65.9 & 0.4 \\
O 1s & 530.4 & 26.5 & 0.3 & 32.1 & 0.4 \\
\hline
\end{tabular}

Table 1 XPS quantification of the GO sample

CEM I 52.5 N Portland cement (PC, with a chemical composition of $0.3 \% \mathrm{Na}_{2} \mathrm{O}, 0.4 \% \mathrm{~K}_{2} \mathrm{O}$,

173 ignition of 1.6\%), conforming to SS EN 197-1 standards [34], was used as the main binder.

174 Along with PC, a polycarboxylate ether (PCE)-based superplasticizer $(\mathrm{pH}=6.25)$ procured 175 from Grace Ltd. (Singapore) and distilled water $(\mathrm{pH}=6.93)$ were used to prepare the GO- 
modified cement pastes. Fig. 2(a) shows the particle size distribution of PC, obtained by using a Malvern mastersizer-2000 analyser. The cement particles ranged from $270 \mathrm{~nm}$ to $154 \mu \mathrm{m}$ in size, a majority of which was between $1.5 \mu \mathrm{m}$ and $154 \mu \mathrm{m}$, whereas the average size was 29 $\mu \mathrm{m}$. XRD spectra of cement and GO (Fig. 2(b)) were obtained by using a Bruker D8 Advance $\mathrm{X}$-ray diffractometer with a $\mathrm{Cu} \mathrm{K} \alpha$ source, operating at $40 \mathrm{~mA}$ and $40 \mathrm{kV}$. The scanning range was $5-80^{\circ} 2 \theta$, and the rate was $0.02^{\circ} 2 \theta / \mathrm{min}$. The major oxide compounds in cement were identified as $\mathrm{C}_{3} \mathrm{~S}, \mathrm{C}_{2} \mathrm{~S}, \mathrm{C}_{3} \mathrm{~A}$, and $\mathrm{C}_{4} \mathrm{AF}$. The major peaks in the $\mathrm{GO}$ sample confirmed its graphitic structure.
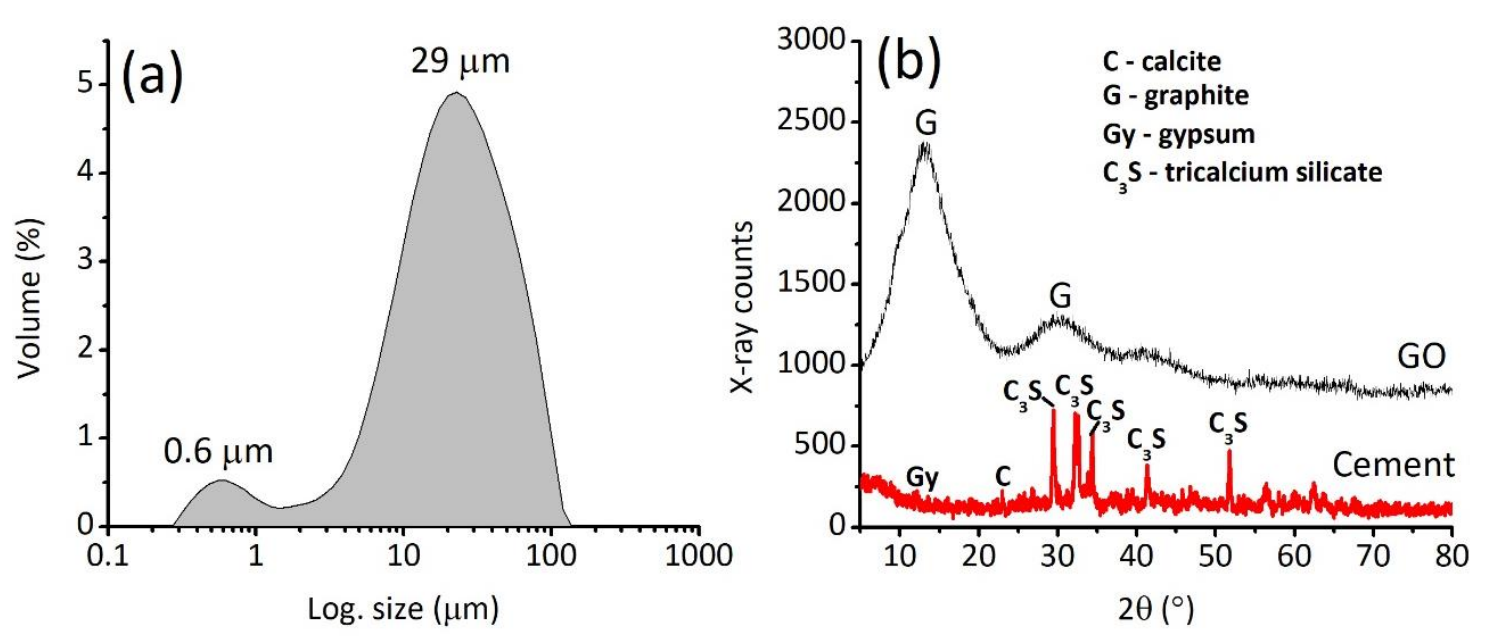

Fig. 2 Initial analysis of the materials, showing (a) the particle size distribution of PC and (b) XRD patterns of $\mathrm{GO}$ and $\mathrm{PC}$

\subsection{Sample preparation}

Seven paste mixes including different concentrations of GO $(0 \%, 0.015 \%, 0.03 \%, 0.045 \%$, $0.06 \%, 0.075 \%$, and 0.09 wt. $\%$ ) were prepared and labelled as GO-0, GO-1, GO-2, GO-3, GO4, GO-5, and GO-6, respectively. Table 2 shows a list of the different cement mixes prepared in this study. All mixes had the same water to cement (w/c) ratios and PCE contents of 0.35 and $0.1 \%$ by weight of cement, respectively. Before the fresh cement mixes were prepared, the aqueous solution containing GO, superplasticizer, and water was sonicated for 20 minutes using a Qsonica probe sonicator, operated at a power of $50 \mathrm{~W}$. The sonicated solution was hand-mixed with cement for 2 minutes at $25^{\circ} \mathrm{C}$, cast in acrylic moulds $\left(15 \times 15 \times 50 \mathrm{~mm}^{3}\right)$, and 
consolidated for 40 seconds on a vibration table. After 24 hours, the specimens were demoulded and placed in a curing tank for 2 weeks.

Table 2 GO contents in the cement mixes prepared in this study

\begin{tabular}{cc}
\hline Mix ID & GO $(\%)$ \\
\hline GO-0 & 0 \\
GO-1 & 0.015 \\
GO-2 & 0.03 \\
GO-3 & 0.045 \\
GO-4 & 0.06 \\
GO-5 & 0.075 \\
GO-6 & 0.09 \\
\hline
\end{tabular}

207

\subsection{Calorimeter and rheometer tests}

210 The heat of hydration of each mixture was studied by a high precision isothermal calorimeter

211 (Calmetrix I-Cal 8000 HPC), according to ASTM C1702-15a [35]. After mixing with distilled water (i.e. similar to the preparation of prism samples), the GO-modified cement pastes were placed inside the calorimeter channel within a few seconds to record the heat of hydration for 24 hours. No significant changes were seen in the heat flow curve after the first 24 hours in the initial trial runs. Each mixture was analysed three times to calculate the average heat of hydration.

218 The rheological properties of the fresh GO-modified cement pastes were assessed using a 219 HAAKE Mars III rheometer. The measuring cell in this rheometer was fixed with a $20 \mathrm{~mm}$ diameter base plate (TMP 20) and a titanium-based top plate (P20 Ti L S) with a sensor arrangement. After several trials run, this cell fixture was chosen to determine the shear stress $(\tau)$, and apparent viscosity $(\mu)$ of GO-modified cement pastes at $25^{\circ} \mathrm{C}$ and $65 \%$ relative humidity (RH). A spoonful of 2-min hand-mixed cement paste was placed on to the measuring cell fixture and pressed against the base plate at a load of $0.5 \mathrm{~N}$. Any excess cement paste was scraped off the sides. The top plate was rotated at a speed of 50 RPM for 30 seconds to break 
down the existing flocculation in the fresh paste. This was followed by an increase in the shear rate from 1 to $100 \mathrm{~s}^{-1}$ within 100 seconds. The rheological data was recorded for 130 seconds in total, in line with the findings of previous studies [36]. Each test was repeated four times to assess the reproducibility of $\tau$ and $\mu$ values for each mix.

\subsection{Acid attack}

Lab reagent $37 \%$ concentrated $\mathrm{HCl}$ procured from Sigma Aldrich was used in this study. The extent of acid attack on GO-modified cement pastes was investigated by immersing cured prism specimens (i.e. in wet state) inside a $150 \mathrm{~mL}$ glass beaker containing a $0.5 \mathrm{M} \mathrm{HCl}$ solution for four weeks. Each prism sample was placed in the beaker in an inclined position to ensure that all surfaces were in contact with the $\mathrm{HCl}$ solution for uniform exposure. A constant temperature of $25^{\circ} \mathrm{C}$ and $\mathrm{RH}$ of $65 \%$ was maintained throughout the exposure period. The $\mathrm{HCl}$ solution was replenished every week during the 4-week testing period.

\subsubsection{Mass and sectional area}

Two prism samples from each mix were exposed to $\mathrm{HCl}$ solution. The changes in the masses of these specimens were monitored during the 4-week testing period using a mass balance with a $0.001 \mathrm{~g}$ accuracy. Before the measurements, the free surface solution was wiped from the degraded specimens by using a dry and clean tissue paper. After four weeks of acid exposure (Fig. 3), the specimens were carefully sectioned into multiple pieces, each with a thickness of $10 \mathrm{~mm}$, by using a Buehler Isomet 1000 precision diamond saw. These cut sections were dried under $25^{\circ} \mathrm{C}$ for 3 days before they were analyzed under an Optem Zoom 70XL stereo microscope with a high magnification lens (Fig. 4). The discoloured and altered regions within the cut sections of the damaged specimen were identified via an image analysis software to determine the loss in the sectional area. The area of the altered zone was calculated by adjusting the image brightness to precisely locate the boundaries of the discoloured zone, calibrating the image size and measuring the area of the discoloured region. The average decline in the sectional area was calculated. 


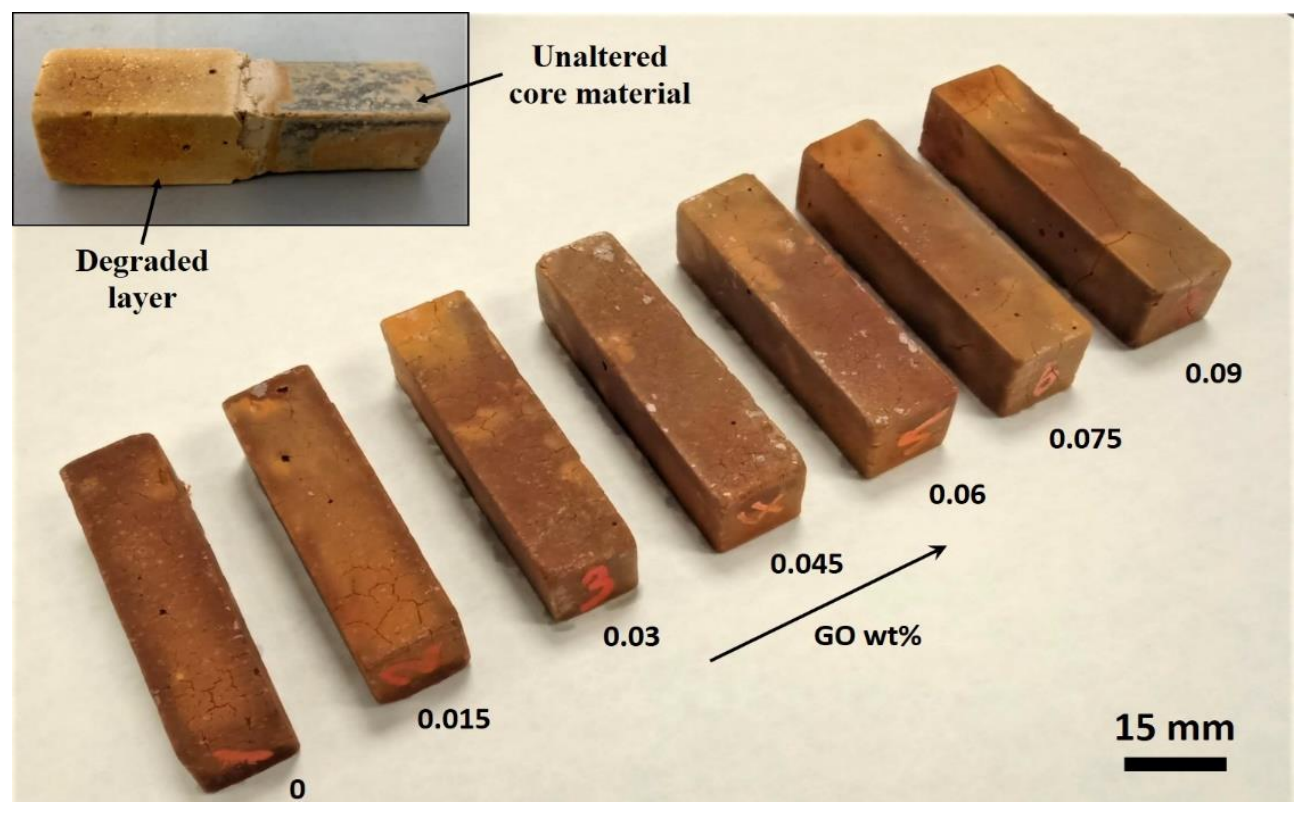

Fig. 3 Cement specimens at the end of $\mathrm{HCl}$ exposure (i.e. inset picture showing the degree of alteration in the acid exposed cement matrix)

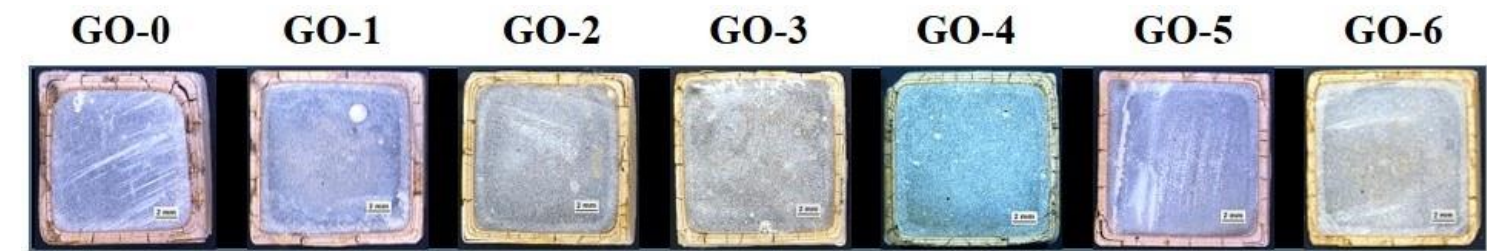

Fig. 4 Cut section showing the altered zone in the cement matrix subjected to $\mathrm{HCl}$ attack

\subsection{2 pH, conductivity, and ICP-OES analyses}

The changes in $\mathrm{pH}$ and conductivity $(\mathrm{k})$ of the $\mathrm{HCl}$ solution due to cement leaching were analyzed using a Horiba F-52 pH meter and a ThermoScientific A212 conductivity meter. Before these analyses, these two meters were subjected to 3-point calibration at $25^{\circ} \mathrm{C}$, in line with NIST standards, and the average of the three was calculated. The concentrations of aluminium and silicon ions remaining in the $\mathrm{HCl}$ solution were detected by a Perkin Elmer Optima 8000 ICP-OES under room temperature. Before the analysis, the $\mathrm{HCl}$ solution was 
filtered using $0.2 \mu \mathrm{m}$ Whatman disk filters, diluted 1000 folds, and acidified with $2 \%$ nitric acid. The average of three readings was calculated.

\subsubsection{SEM-EDS and Vickers micro-hardness test}

The cut sections were vacuum dried under $30^{\circ} \mathrm{C}$ for 2 days before they were analysed by a JEOL JSM-7600F SEM-EDS. The top surfaces of the dried samples were sputter-coated with platinum for 60 seconds to minimise charging before analysis under the secondary electron (SE) mode. Selected segments were epoxy impregnated using a Buehler Cast N' Vac 220 vacuum impregnation device and left undisturbed for 8 hours. The hardened epoxy polymer was demoulded and polished according to the procedure suggested in a previous study [37] by using a grinding-polishing machine (Buehler MetaServ 250). These polished sections were used in the EDS and backscattered electron (BSE) analyses.

The micro-scale hardness measurements were conducted on the polished sections by using a Wilson Tukon-1202 Vickers hardness tester, according to ASTM E384-17 [38]. With the use of an optical microscopy fixture, the region of interest in the glossy surface was imaged, and indent was created by applying a load (P) of 0.3 kilogram-force (kgf) over a loading time of 10 seconds. Multiple indents were carried out on the hydrated cement matrix by omitting the voids and unhydrated cement clinker (i.e. before acid attack), and in the altered zone of the cement matrix (i.e. after acid attack). The two opposite diagonal lengths ( $\mathrm{d}_{1}$ and $\mathrm{d}_{2}$ ) of each indent mark were recorded. The Vickers hardness number (HV0.3) was calculated by dividing 1.854xP (kgf) with the area of indentation $\left(\mathrm{mm}^{2}\right)$, which was determined by multiplying the two diagonal lengths $\left(d_{1}\right.$ and $\left.d_{2}\right)$ of each indent [39].

\subsubsection{FT-IR, XRD, and TGA}

Segments extracted from the altered zone before and after acid exposure were vacuum dried and ground down by using a mortar and pestle to a size $<54 \mu \mathrm{m}$. The powdered samples were characterised via FT-IR, XRD and TGA. The mid-IR scan was performed within the wavelength range of $4000-400 \mathrm{~cm}^{-1}$ by using a Thermo Scientific Nicolet iS50 model FT-IR instrument. XRD data were collected within the $5-80^{\circ} 2 \theta$ range, at a scanning rate of $0.02^{\circ} / \mathrm{min}$ 
by a Bruker D8 Advance XRD machine. TGA was performed via a Perkin Elmer 4000, during which the powdered sample was heated from $35^{\circ} \mathrm{C}$ to $900^{\circ} \mathrm{C}$ at a rate of $10^{\circ} \mathrm{C} / \mathrm{min}$, under a

313 nitrogen environment.

\section{RESULTS AND DISCUSSION}

\subsection{Heat of hydration}

Fig. 5 shows the calorimetry results of GO-modified cement pastes during the first 24 hours of hydration. Out of all the samples analysed, GO-1 and GO-2 exhibited the highest heat flow, which was more evident during the first 10 hours. These results revealed the role lower GO dosages played in accelerating the rate of heat evolution. Alternatively, as the GO dosage increased beyond $0.03 \%$, retardation in hydration was observed.

A similar outcome was reported by previous studies [40-43], where an acceleration in the hydration of cement mixes was found with a GO addition of $0.02 \mathrm{wt} . \%$, which improved the polymerisation of calcium silicate hydrate (C-S-H) and thus led to increased strengths. Accordingly, GO with a high surface area and oxygen-containing functional groups available at the graphene surfaces can electrostatically interact with the $\mathrm{Ca}^{2+}$ ions from the dissolution of $\mathrm{C}_{3} \mathrm{~S}$ and $\mathrm{C}_{3} \mathrm{~A}$ and function as nucleation sites to accelerate the hydration process [40, 44-46]. On the other hand, when introduced at higher dosages, GO may absorb onto the surfaces of cement, and thereby retarding hydration. This retardation effect of high GO contents was also reported earlier [22], where the limitations in the dissolution of calcium aluminates were mentioned. Therefore, these findings shown in Fig. 5 were in line with these mechanisms, highlighting the importance of GO content in enhancing the reaction mechanisms of PC mixes. 


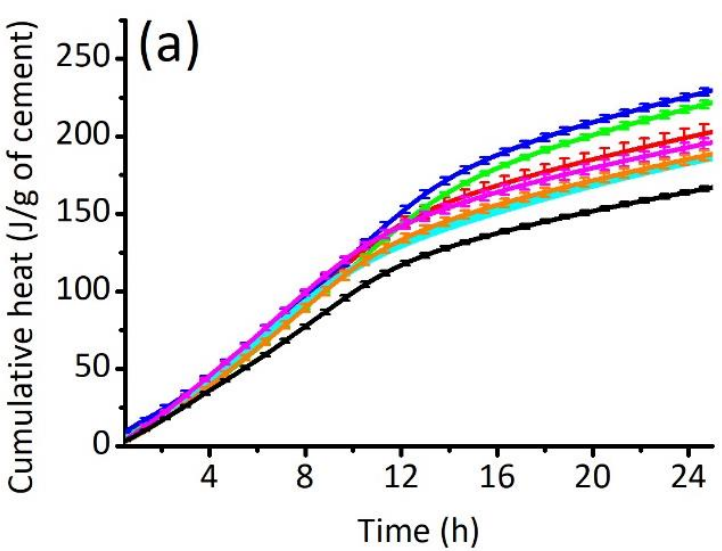

Time (h)

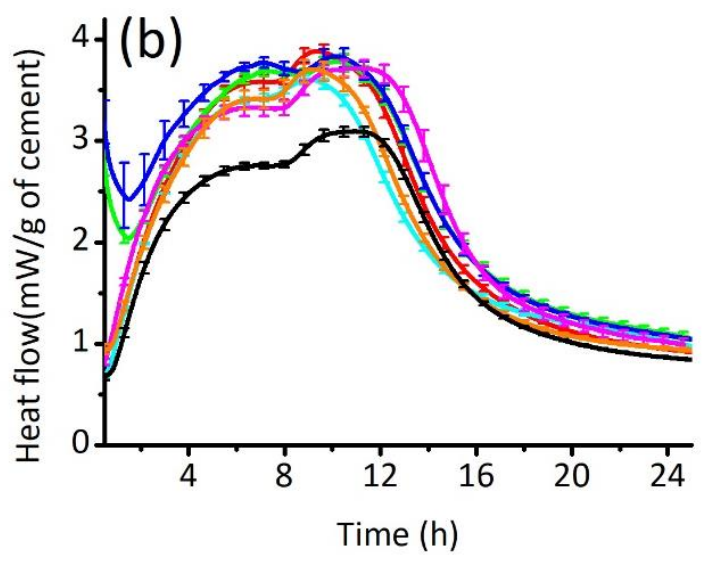

GO-3 - GO-4 - GO-5 - GO-6

Fig. 5 Isothermal calorimetry results, showing (a) cumulative heat (energy vs. time) and (b) heat flow (power vs. time) curves

\subsection{Rheological properties}

Fig. 6 presents the rheological data such as the shear stress $(\tau)$ and apparent viscosity $(\mu)$ of the GO-modified cement pastes. The results demonstrated in Figs. 6(a) and (b) revealed the shearthinning behaviour of the fresh cement mixes. Out of the different rheological prediction models that were used to fit the experimental rheological data of GO-modified cement pastes (e.g., modified Bingham, Herschel-Bulkley, Bingham and Casson models), the HerschelBulkley model was found to fit the experimental data best [47]. The details of this model are shown in Equation 1, where $\tau$ is shear stress $(\mathrm{Pa}), \tau_{0}$ is yield shear stress $(\mathrm{Pa}), \mathrm{K}$ is consistency $\left(\mathrm{Pa} . \mathrm{s}^{\mathrm{n}}\right), \curlyvee$ is the shear rate $\left(\mathrm{s}^{-1}\right)$, and $\mathrm{n}$ is a power rate index or pseudo-plastic index. According to this model, a minimum shear stress is required to initiate flow, but smaller increment in stress with increasing shear. The GO-modified cement pastes demonstrated a similar flow behaviour, as shown in Figs. 6(a) and 6(d).

$\tau=\tau_{0}+\mathrm{K}(\Upsilon)^{\mathrm{n}}$

Regardless of the GO dosage, the apparent viscosity of the fresh cement pastes decreased with an increase in the shear rate (Fig. 6(b)), indicating that the cement particles and GO sheets progressively separated and aligned in the direction of flow. Higher GO dosages led to 
increased initial shear stress and viscosity values (Figs. 6(c) and 6(d)), suggesting that the inclusion of high GO dosages could reduce the workability of the paste. The initial shear stress and viscosity values of the fresh pastes were determined at a shear rate of $1 \mathrm{~s}^{-1}$. The change in the initial shear stress from GO-3 to GO-4 could be an indication of the formation of flocculated structures due to the agglomeration of GO and cement particles when the GO dosage exceeded $0.06 \mathrm{wt} . \%$ in the cement paste. Conisdering that the fluidity of the fresh cement paste was also controlled by the thickness of the water film surrounding the cement particles [48], the adsorbtion of free water onto the GO surfaces rather than the cement particles in GO-4, GO-5, and GO-6 samples could drastically reduce the fluidity of these pastes. With an increase in GO dosage, the deformation of the cement pastes under the external force became more difficult due to the reduced distance between each particle.

The characteristics of GO influencing the hydration kinetics and workability of fresh cement pastes are its size, dispersibility, dosage, and carbon-to-oxygen ratio [25]. When considered together, the calorimeter and rheometer results revealed that the inclusion of $0.09 \mathrm{wt} \% \mathrm{GO}$ significantly reduced the hydration and workability of cement mixes. This could be mainly due to the increased adsorption of free water onto the GO surfaces instead of the cement particles during early ages. In this respect, limiting the GO content in the cement matrix can avoid poor workability and high retardation effect.

382
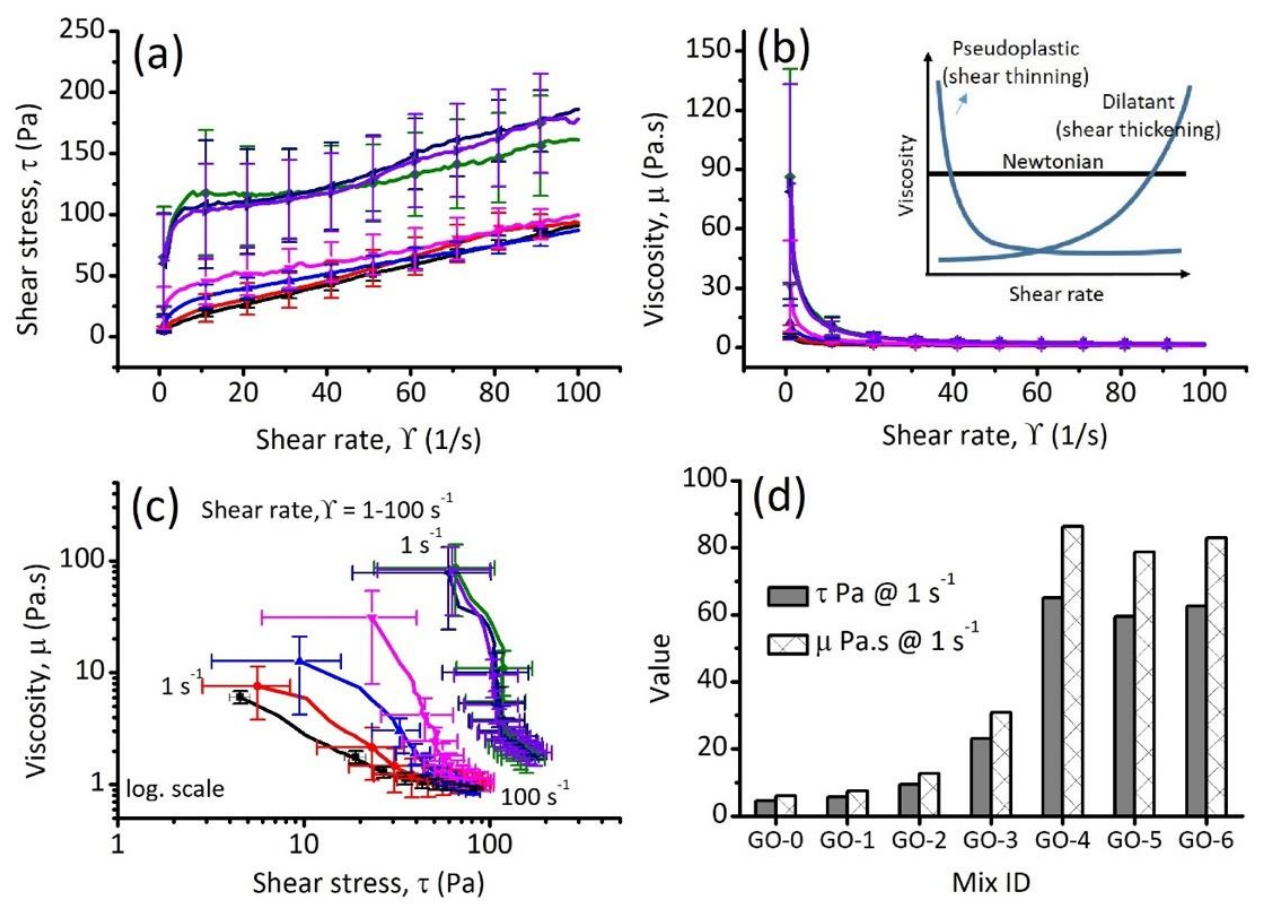
Fig. 6 Rheological properties of the prepared samples, showing (a) shear stress vs. shear rate, (b) viscosity vs. shear rate (insect picture showing the rheological model), (c) viscosity vs. shear stress and (d) initial shear stress and viscosity values obtained at a shear rate of $1 \mathrm{~s}^{-1}$

\subsection{Changes in $\mathrm{pH}$, conductivity and leaching under $\mathrm{HCl}$ exposure}

391

392

Table 3 shows the $\mathrm{pH}$ and conductivity of the $\mathrm{HCl}$ solution recorded weekly over the 4-week testing period, during which the acid solution was replenished weekly. Any changes observed in these values were primarily dependent on the alkalinity of the cement matrix and the leaching of ions from the submerged samples $[4,49]$. The relatively stable $\mathrm{pH}$ values recorded amongst different samples indicated that the inclusion of GO did not alter the alkalinity of the cement paste. The $\mathrm{HCl}$ solution used in this study was strongly acidic with a high k value $(\sim 148$ $\mathrm{mS} / \mathrm{cm})$.

399

Table $3 \mathrm{pH}$ and conductivity (k) values of water (i.e. after curing) and of $\mathrm{HCl}$ solution (i.e. at 401 the end of every week after acid attack)

402

\begin{tabular}{|c|c|c|c|c|c|c|c|c|c|c|}
\hline \multirow[t]{3}{*}{ Mix ID } & \multirow{2}{*}{\multicolumn{2}{|c|}{$\begin{array}{c}\text { Water }{ }^{\#} \text { after } \\
\text { curing }\end{array}$}} & \multicolumn{8}{|c|}{$\mathrm{HCl}^{*}$ solution after acid attack } \\
\hline & & & \multicolumn{2}{|c|}{ Week 1} & \multicolumn{2}{|c|}{ Week 2} & \multicolumn{2}{|c|}{ Week 3} & \multicolumn{2}{|c|}{ Week 4} \\
\hline & $\mathrm{pH}$ & $\mathrm{k}^{\wedge}$ & $\mathrm{pH}$ & $\mathrm{k}$ & $\mathrm{pH}$ & $\mathrm{k}$ & $\mathrm{pH}$ & $\mathrm{k}$ & $\mathrm{pH}$ & $\mathrm{k}$ \\
\hline GO-0 & 11.81 & 1.1 & 4.33 & 30.5 & 3.38 & 34.1 & 3.29 & 34.2 & 3.12 & 42.1 \\
\hline GO-1 & 11.55 & 1.0 & 4.28 & 31.5 & 3.37 & 34.6 & 3.25 & 34.5 & 3.04 & 41.4 \\
\hline GO-2 & 11.73 & 1.0 & 4.16 & 31.1 & 3.34 & 34.4 & 3.14 & 35.0 & 3.01 & 42.3 \\
\hline GO-3 & 11.77 & 0.9 & 4.08 & 32.2 & 3.22 & 34.5 & 3.28 & 34.9 & 3.11 & 43.6 \\
\hline GO-4 & 11.28 & 1.9 & 3.71 & 32.1 & 3.23 & 34.4 & 3.26 & 35.0 & 3.04 & 43.4 \\
\hline GO-5 & 11.71 & 1.0 & 3.97 & 32.4 & 3.17 & 34.6 & 3.23 & 34.9 & 3.01 & 43.6 \\
\hline GO-6 & 11.76 & 1.0 & 4.23 & 32.1 & 3.23 & 34.7 & 3.18 & 34.4 & 3.01 & 43.5 \\
\hline
\end{tabular}


When compared to its initial $\mathrm{pH}(7.73)$ and conductivity $(0.7 \mathrm{mS} / \mathrm{cm})$, the $\mathrm{pH}$ and conductivity of water that was used to cure the GO-0 samples increased by $\sim 1.5$ fold and $\sim 1.6$ fold, respectively. These changes were associated with the leaching of alkalis, free lime, and portlandite from the sample into the curing water. The leaching process involved (i) the diffusion of ionic species $\left(\mathrm{Ca}^{2+}\right.$ and $\left.\mathrm{OH}^{-}\right)$in the pores of the cement matrix due to the concentration gradients between the pore solution and the external solution and (ii) the dissolution of Ca-based binder phases by hydrolysis to supply $\mathrm{Ca}^{2+}$ ions to maintain equilibrium [4].

Submerging the samples in the $\mathrm{HCl}$ solution led to a significant increase in the $\mathrm{pH}$ of the solution. In contrast, the $\mathrm{k}$ value decreased, indicating potential changes in the composition of the samples under the $\mathrm{HCl}$ environment. Leaching of the cement matrix effectively neutralised the $\mathrm{HCl}$ solution. Accordingly, exposure of the cement matrix to $\mathrm{HCl}$ could have resulted in the formation of $\mathrm{CaCl}_{2}$, as shown in Equations 2 and 3. However, the high solubility of $\mathrm{CaCl}_{2}$ could have led to the leaching of $\mathrm{Ca}^{2+}$ ions into the aqueous solution, contributing to the progression of the leaching front in the cement matrix.

$\mathrm{CaO}_{\text {(free lime) }}+2 \mathrm{HCl} \rightarrow \mathrm{CaCl}_{2}+\mathrm{H}_{2} \mathrm{O}$

$\mathrm{Ca}(\mathrm{OH})_{2}$ (portlandite) $+2 \mathrm{HCl} \rightarrow \mathrm{CaCl}_{2}+\mathrm{H}_{2} \mathrm{O}$

Reduction of the $\mathrm{pH}$ of the pore solution within the samples exposed to $\mathrm{HCl}$ could disturb the chemical equilibrium of these mixes, causing the gradual hydrolytic decomposition of cement hydrates. Accordingly, portlandite starts to dissolve when the $\mathrm{pH}$ falls below 12.5 , followed by ettringite $(\sim 10.6), \mathrm{C}-\mathrm{S}-\mathrm{H}(\sim 10.5)$, and finally, the clinker compounds. Under such conditions, all these components successively degrade until an amorphous alumina-silica hydrogel residue is precipitated [10]. During the dissolution of ettringite and monosulfate, the magnesium and ferrous ions from these components move through the pore solution. The concentration gradients enhance the diffusion of these ions at the exposed surface, where they precipitate as hydrotalcite and iron-substituted C-S-H [50]. These secondary precipitates indicate the alumina, silica, and iron enrichment found in the altered region of the cement matrix subjected to acid attack [51]. The severity of the acid attack is dependent on the solubility of these secondary precipitates, and the stability of salt and hydrogel precipitated in the altered zone 
[4]. Faucon et al. [50] pointed out the importance of alumina and ferrous ions as stabilising agents in this protective layer.

Measurements of solution conductivity confirmed that ion-exchange and mass transfer between the cement matrix and surrounding solution was higher under $\mathrm{HCl}$ exposure than in water. The leaching of samples increased the $\mathrm{k}$ value of water by $28-171 \%$, but decreased that of $\mathrm{HCl}$ solution by $69-79 \%$. This decline in the $\mathrm{k}$ value of the $\mathrm{HCl}$ solution was an indication of the presence of a high amount of hydrogen ions (i.e. originating from the acid solution) in the cement matrix, decalcification of the compounds and re-precipitation of the calcium-based salt in the external solution. These findings corresponded to the reduction in the conductivity of the solution (i.e. a measure of ions existing in the solution), which was associated with the precipitation of the calcium-based salt. Besides, the most notable change in the $\mathrm{pH}$ of $\mathrm{HCl}$ solution before and after exposure was observed in the first week and reduced in the successive weeks. This outcome suggested that the altered zone could be acting as a protective barrier at the interface between the $\mathrm{HCl}$ solution and the remaining unaltered zone.

The ionic strength could be inferred using the conductivity data, as shown in several previous studies $[52,53]$. In this study, the percentage change in the conductivity of the $\mathrm{HCl}$ solution due to immersion of the GO-0 sample for one week was 79\%; whereas this change in the case of the GO-6 sample was 78\%. These results could be an indication that the inclusion of GO sheets did not have a major effect in terms of the penetration of hydrogen ions from the acid into the cement matrix, despite the trend shown in the mass loss and sectional area results. Accordingly, Table 4 shows the concentrations of alumina and silica ions in the $\mathrm{HCl}$ solution at the end of the first week. As can be seen, when the cement matrix was reinforced with 0.06 wt.\% GO, the removal of alumina (Al) and silicon (Si) ions reduced 2.6 and 2.3 folds, respectively. A similar finding was reported by Long et al. [54], where the removal of $\mathrm{Ca}^{2+}$ ions from a $0.2 \mathrm{wt} . \%$ GO-modified cement composite in the deionized water was $17 \%$ less than that from the control sample without the inclusion of GO.

Table 4 Change in alumina and silicon concentrations in the $\mathrm{HCl}$ solution 467

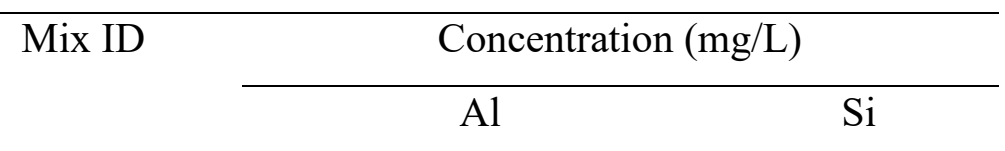




\begin{tabular}{lll}
\hline GO-0 & 47 & 52 \\
GO-3 & 44 & 50 \\
GO-6 & 18 & 23 \\
\hline
\end{tabular}

Note: $\mathrm{Al}$ and $\mathrm{Si}$ concentrations in the $\mathrm{HCl}$ solution before acid attack test were 0.3 and $0.1 \mathrm{mg} / \mathrm{L}$, respectively.

468

469

470

471

472

473

474

475

476

477

478

479

480

481

482

483

484

485

486

487

488

489

490

491

492

493

494

\subsection{Mass loss and sectional area loss under HCl expsoure}

Some of the main signals of leaching of cement-based materials exposed to acid attack are the losses in their alkalinity, mass, strength, and rigidity [4]. The rate of such material degradation can be described by Fick's law, relating the thickness of the altered zone to the square root of acid immersion time [55]. The average depth of the degraded zone in the GO-0, GO-1, GO-2, GO-3, GO-4, GO-5, and GO-6 samples were recorded as 1.23, 1.01, 0.95, 0.86, 0.79, 0.83, and $0.71 \mathrm{~mm}$, respectively. Fig. 7 shows the losses in mass and sectional area within these GOmodified cement pastes under different acid exposure durations. After four weeks of exposure, the control sample (GO-0) revealed notable mass and sectional area losses of $\sim 21 \%$ and $\sim 29 \%$, respectively. On the other hand, the losses in mass and sectional area reduced with increasing GO dosage. Accordingly, the mass and sectional area losses of GO-6 samples after four weeks of acid storage were $\sim 16 \%$ and $\sim 20 \%$, respectively. These losses were associated with the alteration of sample structure under acid, which was controlled by (i) the diffusion of aggressive acid species through the solution and their contact with the exposed concrete surface and (ii) the chemical processes occurring at these surfaces.

The leaching processes coarsened the cement microstructure, thereby affecting the permeability of the samples. Degradation of samples was determined by the thickness and the diffusion resistance of the altered zone. The altered zone formed in this study was very soft, resulting in its easy separation from the unaltered zone. In the case of GO-modified samples, the reduced changes in mass and sectional area could be attributed to the pore-filling effect caused by the reinforcement provided by the GO sheets in the cement pastes. Furthermore, the carboxyl groups attached to the GO edges could effectively protonate under acid, having a $\mathrm{pH}$ lesser than 1 [56]. In this study, the interaction of the acid with the GO sheets, and thus the 
dissolution of C-S-H gel under the $\mathrm{HCl}$ attack, could have been delayed within GO-modified cement pastes.

While the inclusion of $0.09 \mathrm{wt} . \%$ GO greatly retarded the heat flow in comparison to other samples, the use of GO at such high dosages could have played a role in the protection of the hydrate phases when exposed to $\mathrm{HCl}$ attack. This could be associated with the relatively poor inter-connectivity of the capillary and gel pores in the GO-6 sample, explaining the largest difference in the mass loss and sectional area loss results in comparison to the GO-0 sample.

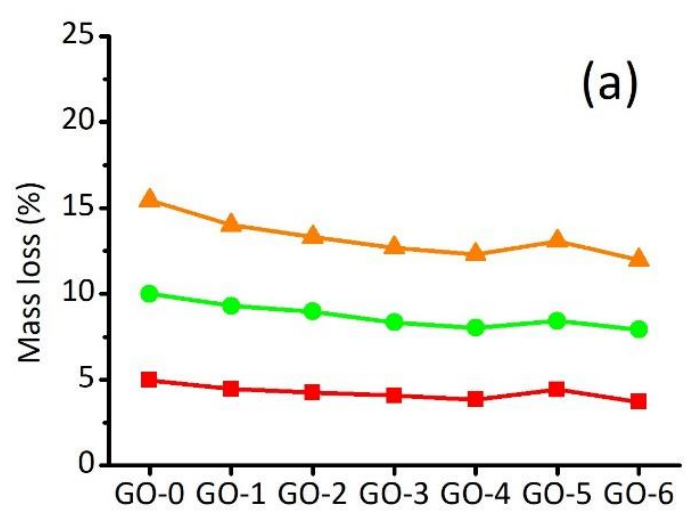

-Week 1-O-Week 2 1 -Week 3

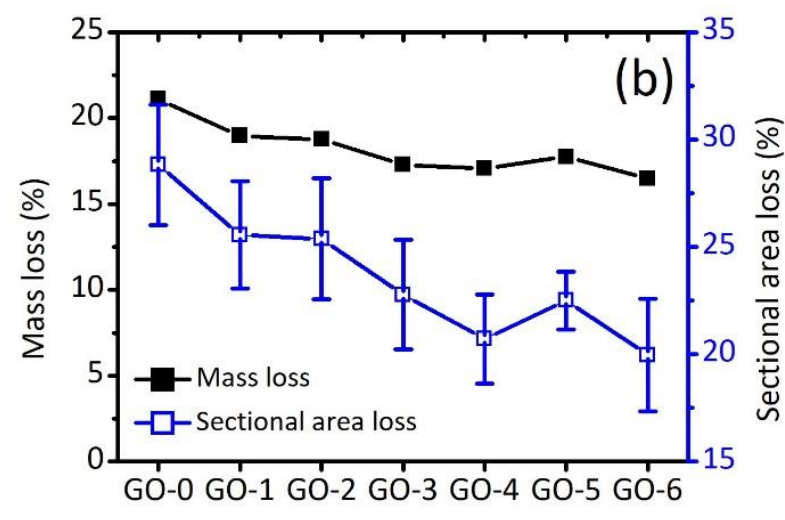

Week 4

Fig. 7 Loss in sample (a) mass and (b) sectional area under $\mathrm{HCl}$ attack

\subsection{Mechanical, chemical and mineralogical analyses of the altered zone}

\subsubsection{SEM-EDS}

Fig. 8 shows the SE and BSE images of the cut sections of GO-0 and GO-6 samples after the $\mathrm{HCl}$ attack. The altered zones in GO-0 and GO-6 samples revealed four separate rings, which could correspond to four times of weekly acid replenishment. Microcracks were observed in the altered zone due to decalcification-induced shrinkage. Such cracks could have formed because of differential decalcification shrinkage. Chen et al. [11] reported the generation of differential stresses due to this decalcification induced shrinkage, which placed the concrete surface in tension. If such tensile stress is enough to cause a fracture, shallow cracks at the 
520

microscale level may form at the concrete surface, which is commonly observed during the drying of C-S-H or other porous gels [57].
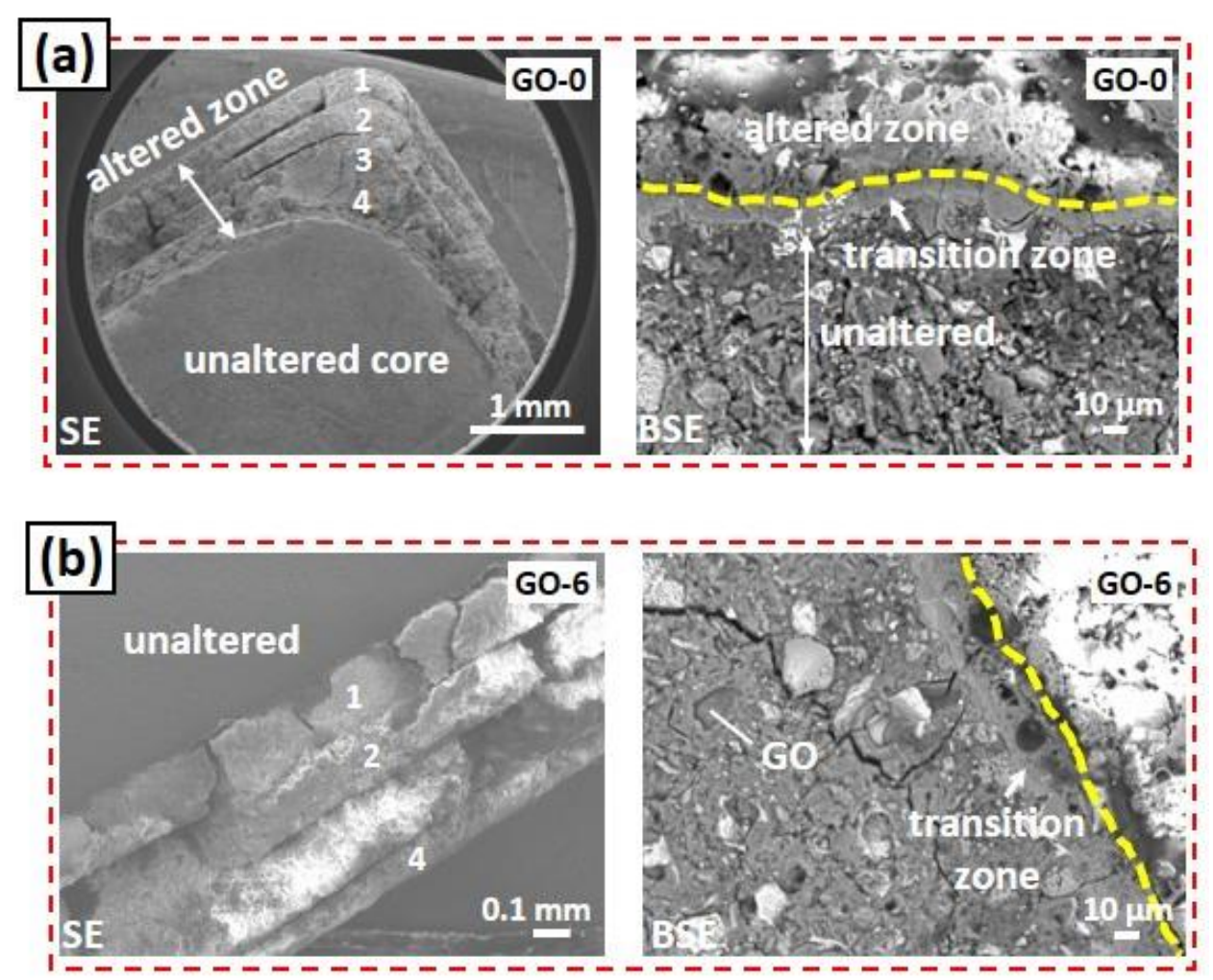

Fig. $8 \mathrm{SE}$ and BSE images of the cut sections of (a) GO-0 and (b) GO-6 samples after $\mathrm{HCl}$ attack

The BSE images revealed the presence of different cement hydrates and clinker components, which possessed different greyscale levels. A transition zone between the altered and unaltered zones was visible in the BSE images, where the presence of portlandite was not observed. As this zone seemed to be less porous than the altered and unaltered zones, it may have resisted the initial ingress of acid species by acting as a protective barrier. In addition to the transition zone, GO used in the prepared mixes was identified via its dark grey tone, which was further confirmed via its EDS data and sheet-like morphology.

Fig. 9 shows the SEM image of the fractured surfaces of GO-0 and GO-6 samples before and after the $\mathrm{HCl}$ attack. Before the acid attack, the presence of C-S-H (i.e. sheet-like morphology) and ettringite (i.e. needle-like morphology) was observed in both mixes (Fig. 9(a)). The presence of GO with a twisted/wrinkled sheet-like morphology, interlaced within the calcium 
hydroxide crystals, was also revealed in the GO-6 sample. Subjecting these samples to the $\mathrm{HCl}$ attack resulted in a notable decalcification of C-S-H gel, portlandite, ettringite, monosulfate, and clinker phases in both blends and led to their precipitation in the form of clusters and porous gel-like structure (Fig. 9(b)). The precipitates were identified as silica hydrogel, in which the GO sheets were intermixed.

546
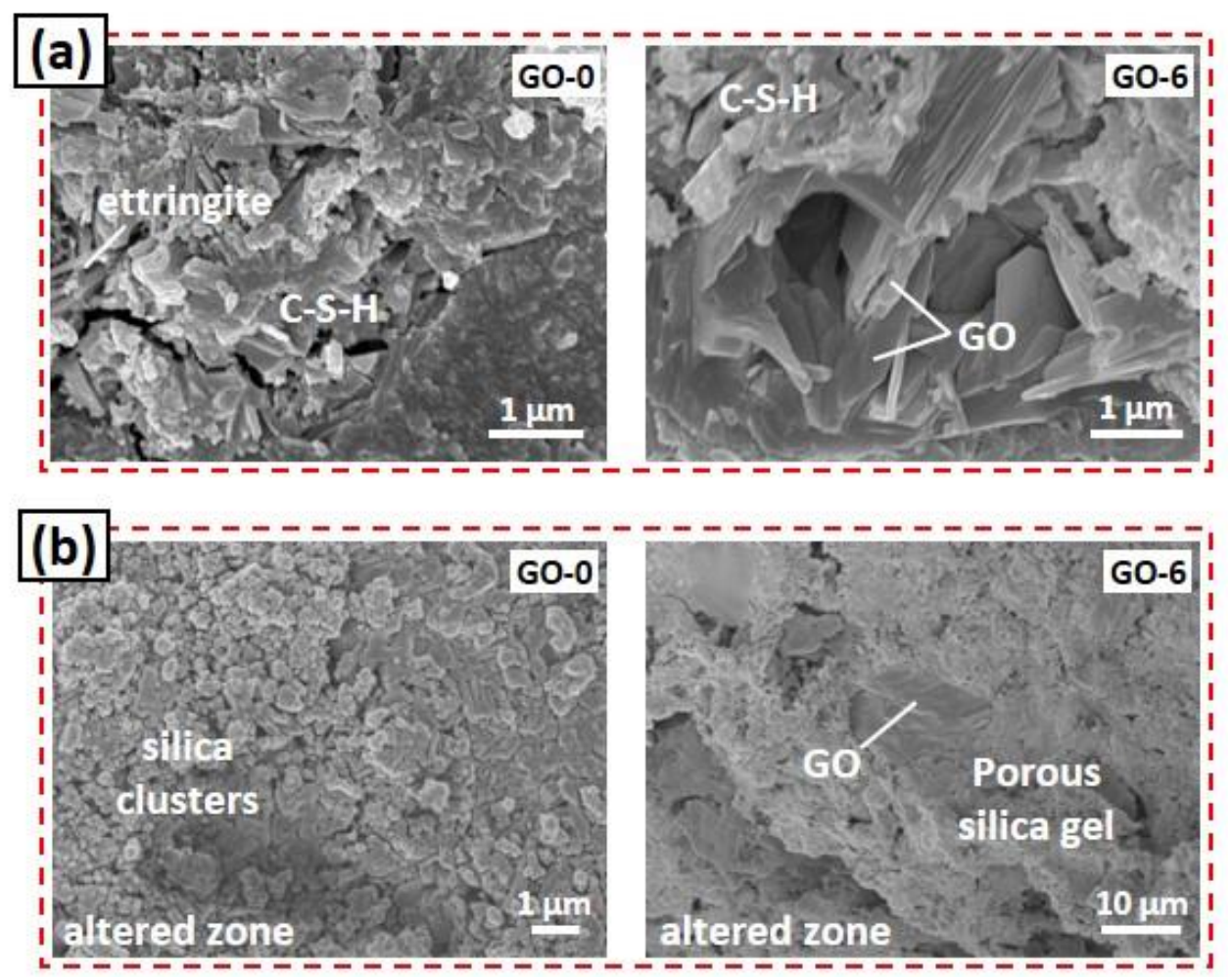

Fig. 9 SE images of the fractured surfaces of GO-0 and GO-6 samples (a) before and (b) after $\mathrm{HCl}$ attack (i.e. the altered zone)

Multiple EDS points were collected on the polished surfaces of the samples before and after (i.e. altered zones) $\mathrm{HCl}$ attack. Fig. 10 shows the 2-dimensional (2D) scatter plots that were drawn by using the atomic ratios calculated from the EDS point analyses. This presentation format enabled the identification of different hydrate phases such as C-S-H, ettringite, monosulfate and portlandite. Several points corresponding to portlandite and ettringite regions were observed in the cured GO-0 and GO-6 samples (Fig. 10, cyan points). These products were missing in the altered zone of the GO-0 sample after the $\mathrm{HCl}$ attack (Fig. 10(a), red points). Instead, the points were in a region corresponding to high alumina, high silica, and low calcium contents in the scatter plots, representing the decalcified ettringite, monosulfate, and 
561 C-S-H. This data was an indication of the decalcifying within the GO-0 sample. Alternatively,

(a) GO-0

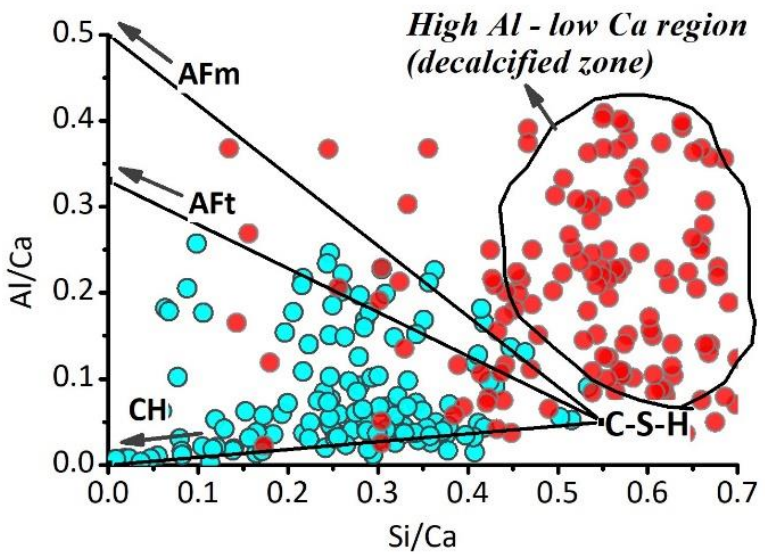

(b) $\mathrm{GO}-6$

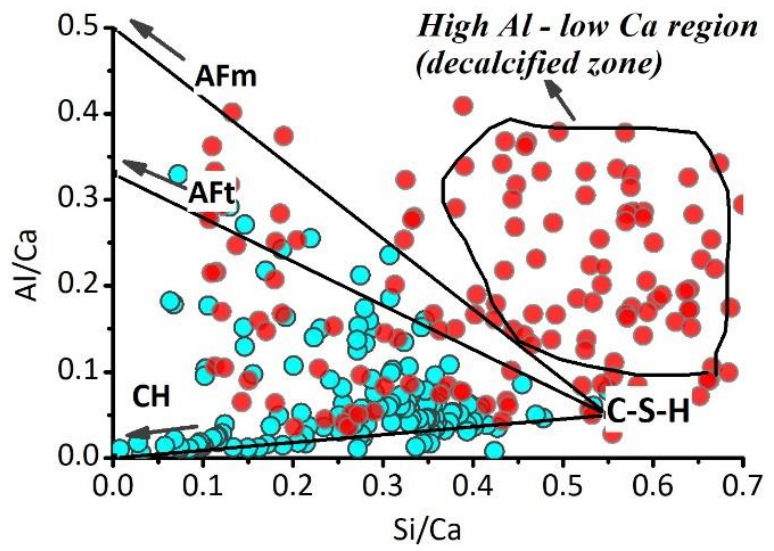

- Before $\mathrm{HCl}$ attack

After $\mathrm{HCl}$ attack

Fig. 10 SEM-EDS scatter plots of (a) GO-0 and (b) GO-6 samples before and after $\mathrm{HCl}$ attack (i.e. the altered zone)

\subsubsection{Vickers hardness}

Fig. 11 presents the micro-hardness of GO-0, GO-3, and GO-6 samples before and after (i.e. the altered zone) $\mathrm{HCl}$ attack. The average Vickers hardness numbers (HV0.3) of GO-0, GO-3, and GO-6 samples were recorded as 100, 107, and 104, respectively. The general increase in the hardness number in the presence of GO sheets could be an indication of the improved hardness of the cement composite, enabled by the enhancement of the bond with hydrate phases such as $\mathrm{C}-\mathrm{S}-\mathrm{H}$ gel. The notable effect of $\mathrm{HCl}$ attack on the mechanical performance of all samples was revealed by the obvious decrease in their average Vickers hardness numbers, which reduced to 17, 19 and 23 for GO-0, GO-3, and GO-6 samples, respectively. This was associated with the transition of the cement matrix into a weak and soft material within the altered zone after exposure to the $\mathrm{HCl}$ solution. 


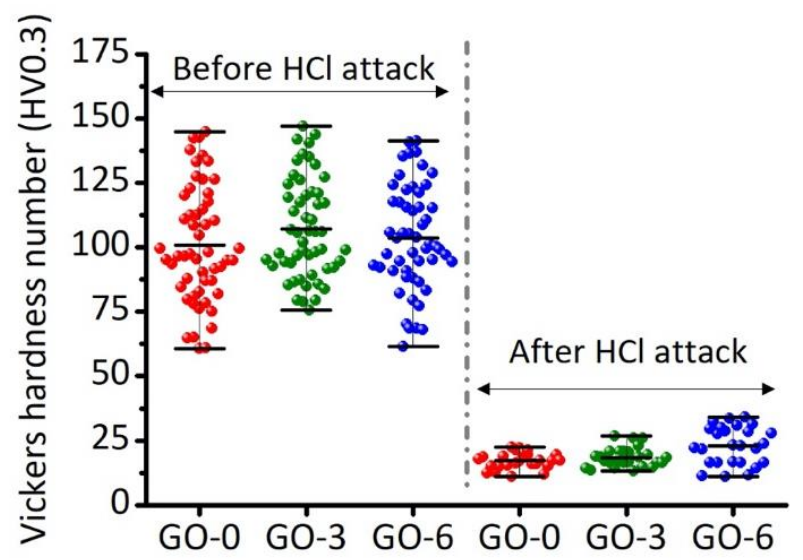

Fig. 11 Vickers micro-hardness number of GO-0, GO-3, and GO-6 samples before and after $\mathrm{HCl}$ attack (i.e. the altered zone).

\subsubsection{FT-IR and XRD}

Figs. 12 and 13 show the FT-IR spectra and XRD patterns of all samples before and after (i.e. the altered zone) $\mathrm{HCl}$ attack. The mid-IR bands associated to $\mathrm{O}-\mathrm{H}\left(\sim 3399 \mathrm{~cm}^{-1}\right.$ and $1654 \mathrm{~cm}^{-}$ $\left.{ }^{1}\right)$, C-O $\left(\sim 1423 \mathrm{~cm}^{-1}\right.$ and $\left.764 \mathrm{~cm}^{-1}\right)$, S-O $\left(\sim 1106 \mathrm{~cm}^{-1}\right)$ and $\mathrm{Si}(\mathrm{Al})-\mathrm{O}\left(\sim 935 \mathrm{~cm}^{-1}\right)$ functional groups indicated the presence of bound water, portlandite, calcite, ettringite, monosulfate and C-S-H in GO-modified samples. These IR bands were noticed in all samples with similar relative intensities, suggesting that GO dosage (i.e. 0.015-0.09 wt.\% ) did not play a significant role in the formation of hydrate phases. A similar finding was revealed by the XRD patterns of these samples, where the presence of peaks at $7.1^{\circ}, 18^{\circ}, 23^{\circ}, 32^{\circ}$, and $50.2^{\circ} 2 \theta$ confirmed the formation of ettringite, portlandite, calcite, and clinker compounds $\left(\mathrm{C}_{2} \mathrm{~S}, \mathrm{C}_{3} \mathrm{~S}\right.$, and $\left.\mathrm{C}_{4} \mathrm{AF}\right)$. Exposure of these samples to the $\mathrm{HCl}$ attack led to a significant change in their chemical compositions, which was also highlighted by the altering of their XRD patterns. Accordingly, the presence of an amorphous hump at $23.8^{\circ} 2 \theta$, indicating the combined presence of quartz $\left(\mathrm{SiO}_{2}\right)$ and gibbsite $\left(\mathrm{Al}(\mathrm{OH})_{3}\right)$, was observed in the XRD spectra of all samples after $\mathrm{HCl}$ attack. The IR bands associated with $\mathrm{O}-\mathrm{H}, \mathrm{Si}(\mathrm{Al})-\mathrm{O}$, and $\mathrm{C}-\mathrm{O}$ functional groups were also noted in their FT-IR ranges. These results were a clear demonstration of the effect of the strong acid environment (i.e. with a weekly replenishment schedule, as used in this study) on the complete dissolution of $\mathrm{C}_{3} \mathrm{~S}, \mathrm{C}_{2} \mathrm{~S}, \mathrm{C}_{4} \mathrm{AF}$ and other hydrate phases; and the appearance of an amorphous alumina-silica hydrogel in all samples after acid exposure. 


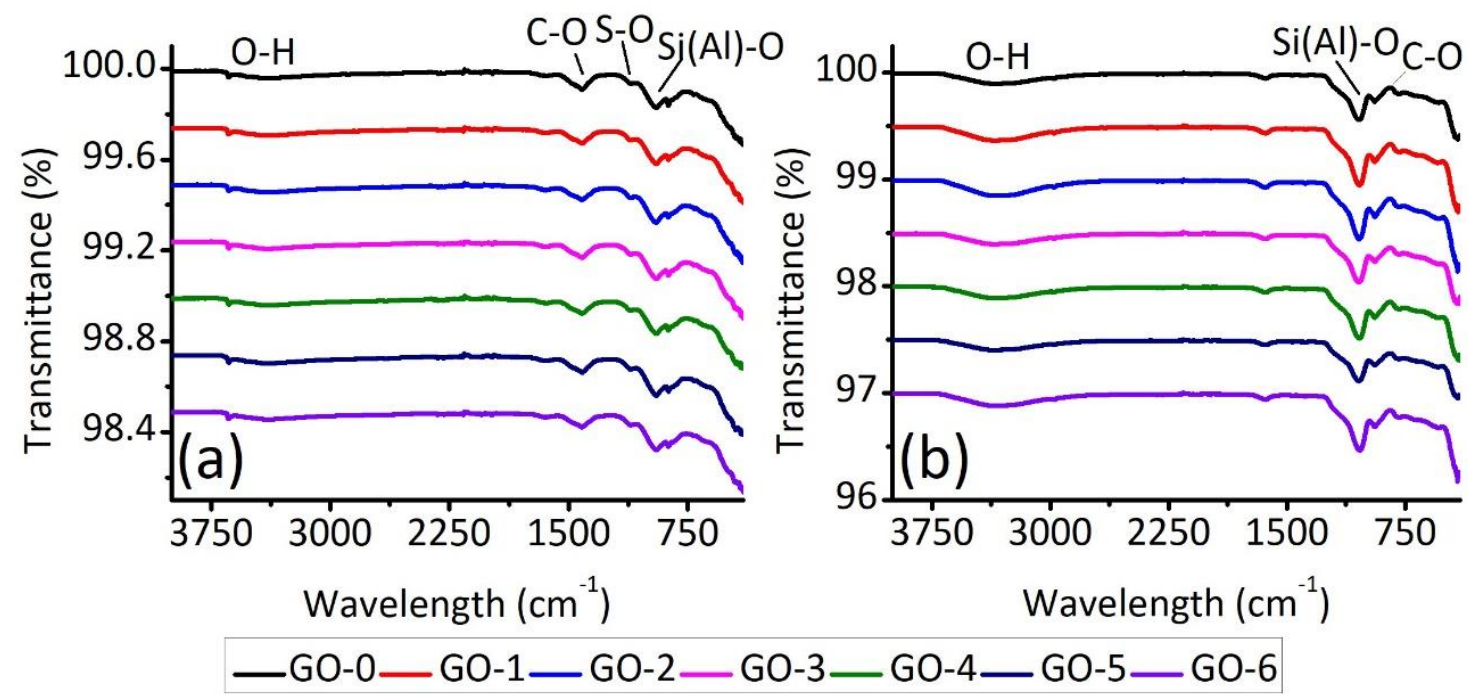

Fig. 12 FTIR spectrum of GO-modified samples (a) before and (b) after $\mathrm{HCl}$ attack (i.e. the

616
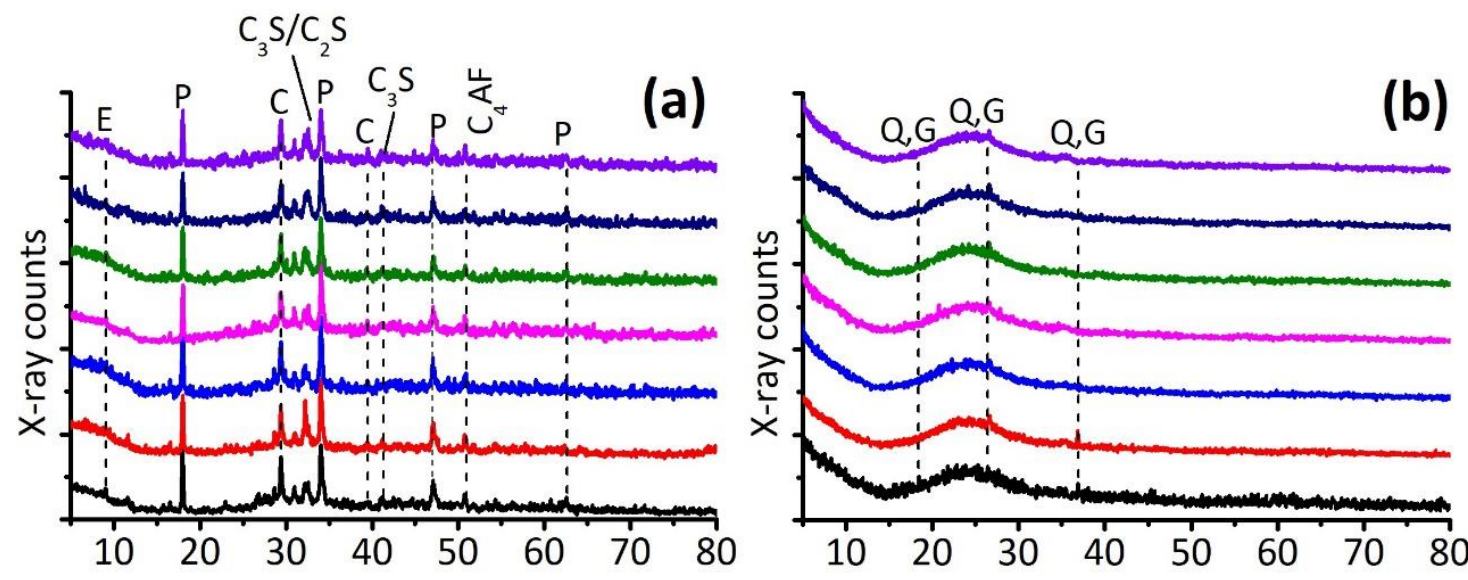

$$
\begin{gathered}
2 \theta\left(^{\circ}\right) \\
-\mathrm{GO}-0-\mathrm{GO}-1-\mathrm{GO}-2-\mathrm{GO}-3-\mathrm{GO}-4-\mathrm{GO}-5-\mathrm{GO}-6
\end{gathered}
$$

E - Etttringite, P - Portlandite, C - Calcite, Q - Quartz, G- Gibbsite $C_{3}$ S - Tricalcium silicate $\mathrm{C}_{2} \mathrm{~S}$ - Dicalcium silicate and $\mathrm{C}_{4} \mathrm{AF}$ - Tetracalcium aluminoferrite

Fig. 13 XRD patterns of GO-modified samples (a) before and (b) after $\mathrm{HCl}$ attack (i.e. the 
625 Fig. 14 shows the TGA results of all GO-modified samples before and after (i.e. the altered 626 zone) $\mathrm{HCl}$ attack. The mass loss due to the evaporable water and dehydroxylation of ettringite $627\left(\sim 30-238^{\circ} \mathrm{C}\right)$, dehydroxylation of portlandite $\left(\sim 399-521^{\circ} \mathrm{C}\right)$ and decarbonation of calcite $628\left(\sim 577-784^{\circ} \mathrm{C}\right)$ were observed in the TGA data. In addition to the mass loss corresponding to 629 chemically bound water (CBW), the mass loss observed at each step was quantified in line with 630 the methodology reported in Scrivener et al. [58]. The obtained results for all samples are listed 631 in Table 5.

632

633 The higher CBW contents of GO-1 and GO-2 samples revealed the contribution of GO addition 634 at a content of $0.015-0.03$ wt. \% to the increased formation of hydrate phases via the effective 635 dispersion of GO at these relatively low contents. These results were in line with the isothermal 636 calorimetry results (Fig. 5), where the higher heat evolved by these two samples was an 637 indication of their enhanced hydration in comparison to the control and other samples. 638 Alternatively, increasing the GO content within GO-6 resulted in the lowest CBW content, 639 which showed that increased amounts of GO in cement mixes could retard the hydration 640 process. Amongst the different hydrate phases, while the portlandite content was comparable 641 in all samples, the ettringite content was marginally higher in GO-1 and GO-2 samples, which 642 could explain their higher CBW contents.

644 Once the samples were exposed to the $\mathrm{HCl}$ environment, any mass loss due to previously 645 observed phases like ettringite, portlandite and calcite was not traced in the TGA data. 646 Accordingly, these crystalline compounds were dissolved under the $\mathrm{HCl}$ attack. Instead, the 647 mass loss due to the dehydroxylation of alumina-silica hydrogel was seen in the altered zones 648 of all samples. This gel content was marginally smaller in the GO-6 sample, where the altered 649 zone was occupied with the remains of GO and alumina-silica gel. 

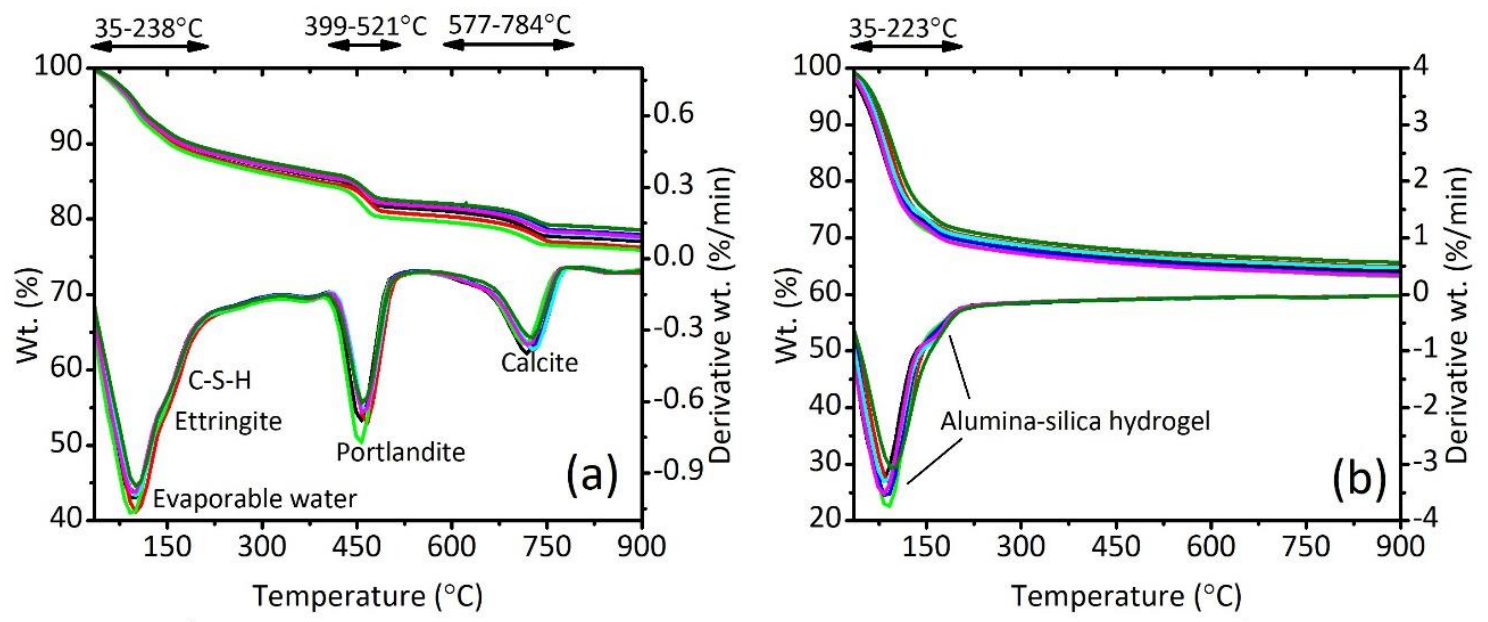

651

- GO-0-GO-1- GO-

GO-3 - GO-4 - GO-5 - GO-6

652

Fig. 14 TGA results of GO-modified samples (a) before and (b) after $\mathrm{HCl}$ attack (i.e. the altered zone)

Table 5 Mass loss (\%) revealed by all samples before and after acid exposure (i.e. the altered

658

\begin{tabular}{ccccccccccc}
\hline Mix ID & \multicolumn{1}{c}{ Before HCl attack } & \multicolumn{7}{c}{ After HCl attack } \\
\cline { 2 - 10 } & TML* & CBW* $^{*}$ & $\mathrm{EW}^{*}$ & $\mathrm{CH}^{*}$ & Calcite & $\mathrm{TML}^{*}$ & $\mathrm{CBW}^{*}$ & Al-Si* & $\mathrm{CH}^{*}$ & Calcite \\
\hline GO-0 & 23 & 19 & 13 & 4 & 4 & 36 & - & 31 & - & - \\
GO-1 & 24 & 20 & 14 & 4 & 4 & 35 & - & 30 & - & - \\
GO-2 & 24 & 21 & 14 & 4 & 3 & 37 & - & 31 & - & - \\
GO-3 & 22 & 19 & 13 & 4 & 3 & 36 & - & 31 & - & - \\
GO-4 & 23 & 19 & 13 & 4 & 4 & 35 & - & 30 & - & - \\
GO-5 & 22 & 19 & 13 & 4 & 3 & 37 & - & 32 & - & - \\
GO-6 & 21 & 18 & 12 & 4 & 3 & 34 & - & 29 & - & - \\
\hline
\end{tabular}

* TML, CBW, EW, CH, and Al-Si refer to total mass loss, chemically bound water, evaporable water, calcium hydroxide (portlandite), and alumina-silica hydrogel, respectively. 
663 This study compared the hydration, rheology, and diffusion resistance of GO-modified cement 664 pastes containing 0-0.09 wt.\% GO under $\mathrm{HCl}$ attack. Constant exposure to $\mathrm{HCl}$ resulted in the 665 formation of a degraded layer surrounding the unaltered zone, regardless of the GO dosage 666 introduced in the blends. The inclusion of 0.015 wt.\% and 0.03 wt.\% GO enhanced the 667 hydration reaction in comparison to the control sample (GO-0). Increasing the GO content 668 beyond this value hindered hydration by inhibiting the dissolution of clinker components at 669 early ages. The fresh GO-modified cement mixes showed shear-thinning behaviour when the material was sheared for 130 seconds. Higher GO dosages beyond 0.045 wt.\% had an obvious effect on cement fluidity, which improved the stability of the fresh cement pastes by bridging the hydrate phases. However, this bridging effect reduced the particle-particle distance, which subsequently decreased the workability of the pastes.

After four weeks of $\mathrm{HCl}$ exposure, a reduced mass loss and sectional area loss were observed in samples containing up to $0.09 \mathrm{wt} . \% \mathrm{GO}$, highlighting the potential of $\mathrm{GO}$ inclusion in improving the resistance of the cement matrix to acid attack. While higher GO dosages affected the workability and hydration of the fresh cement paste, the use of GO improved the diffusion resistance of the cement matrix against $\mathrm{HCl}$ exposure by densifying the microstructure. The presence of alumina-silica hydrogel was observed in the altered zones of the acid exposed specimens. While this chemical change occurred in all GO-modified pastes, the micro-hardness of the sample containing 0.09 wt.\% GO was higher than the control sample (i.e. without any GO), whose micro-hardness was reduced by up to $76 \%$.

Overall, this study paved the way for the enhancement of the resistance of cement-based mixes against aggressive chemical environments, enabling the increase of the service of life of critical structures. The presented results highlighted the role small amounts of GO played in the improvement of the acid resistance of cement samples. Accordingly, the inclusion of up to 0.03 wt.\% GO enhanced the hydration reaction, which could not only be effective in the prevention of the increased formation of microcracks but could also form a protective barrier against aggressive species in extreme environments. Further optimization of the mix design can enable the efficient use of GO that can lead to improvements in sample performance while keeping costs relatively low.

\section{ACKNOWLEDGEMENT}


The authors would like to acknowledge the financial support from the Singapore MOE Academic Research Fund Tier 2 (MOE2017-T2-1-087 (S)) for the completion of this research project. 


\section{REFERENCES}

[1] Y. Fan, S. Zhang, Q. Wang, S.P. Shah, The effects of nano-calcined kaolinite clay on cement mortar exposed to acid deposits, Constr. Build. Mater. 102 (2016) 486-495. https://doi.org/10.1016/j.conbuildmat.2015.11.016

[2] A. Bertron, J. Duchesne, G. Escadeillas, Attack of cement pastes exposed to organic acids in manure, Cem. Concr. Compos. 27(9) (2005) 898-909. https://doi.org/10.1016/j.cemconcomp.2005.06.003

[3] T. Gutberlet, H. Hilbig, R.E. Beddoe, Acid attack on hydrated cement - effect of mineral acids on the degradation process, Cem. Concr. Res. 74 (2015) 35-43. https://doi.org/10.1016/i.cemconres.2015.03.011

[4] M. Alexander, A. Bertron, N. De Belie, Performance of cement-based materials in aggressive aqueous environments, Springer, Dordrecht, Netherlands, 2013. https://doi.org/10.1007/978-94-007-5413-3

[5] V. Pavlík, Corrosion of hardened cement paste by acetic and nitric acids (part I): calculation of corrosion depth, Cem. Concr. Res. 24(3) (1994) 551-562. https://doi.org/10.1016/00088846(94)90144-9

[6] M. Schwotzer, T. Scherer, A. Gerdes, Immediate impact on the rim zone of cement based materials due to chemical attack: A focused ion beam study, Mater. Charact. 99 (2015) 77-83. https://doi.org/10.1016/j.matchar.2014.11.019

[7] J. Camilleri, Characterization of modified calcium-silicate cements exposed to acidic $\begin{array}{lllll}\text { environment, } & \text { Mater. } & \text { Charact. } & 62(1) & \text { (2011) }\end{array}$ https://doi.org/10.1016/j.matchar.2010.10.014

[8] E. Revertegat, C. Richet, P. Gégout, Effect of $\mathrm{pH}$ on the durability of cement pastes, Cem. Concr. Res. 22(2) (1992) 259-272. https://doi.org/10.1016/0008-8846(92)90064-3

[9] J. Jain, N. Neithalath, Analysis of calcium leaching behavior of plain and modified cement pastes in pure water, Cem. Concr. Compos. 31(3) (2009) 176-185. https://doi.org/10.1016/j.cemconcomp.2009.01.003

[10] M. Moranville, S. Kamali, E. Guillon, Physicochemical equilibria of cement-based materials in aggressive environments - experiment and modeling, Cem. Concr. Res. 34(9) (2004) 1569-1578. https://doi.org/10.1016/j.cemconres.2004.04.033

[11] J.J. Chen, J.J. Thomas, H.M. Jennings, Decalcification shrinkage of cement paste, Cem. Concr. Res. 36(5) (2006) 801-809. https://doi.org/10.1016/j.cemconres.2005.11.003

[12] V. Pavlík, Corrosion of hardened cement paste by acetic and nitric acids (part II): formation and chemical composition of the corrosion products layer, Cem. Concr. Res. 24(8) (1994) 1495-1508. https://doi.org/10.1016/0008-8846(94)90164-3

[13] V.r. Zivica, A. Bajza, Acidic attack of cement based materials - a review: Part 1. Principle of acidic attack, Constr. Build. Mater. 15(8) (2001) 331-340. http://dx.doi.org/10.1016/S0950-0618(01)00012-5

[14] S. Türkel, B. Felekoğlu, S. Dulluç, Influence of various acids on the physico-mechanical properties of pozzolanic cement mortars, Sadhana 32(6) (2007) 683-691. https://doi.org/10.1007/s12046-007-0048-0

[15] L. De Ceukelaire, The effects of hydrochloric acid on mortar, Cem. Concr. Res. 22(5) (1992) 903-914. https://doi.org/10.1016/0008-8846(92)90114-B

[16] S. Chandra, Hydrochloric acid attack on cement mortar - an analytical study, Cem. Concr. Res. 18(2) (1988) 193-203. https://doi.org/10.1016/0008-8846(88)90004-X

[17] J. Duchesne, M.A. Be'rube', Effect of supplementary cementing materials on the composition of cement hydration products, Adv. Cem. Based Mater. 2(2) (1995) 43-52. https://doi.org/10.1016/1065-7355(95)90024-1 
[18] B. Lothenbach, K. Scrivener, R.D. Hooton, Supplementary cementitious materials, Cem. Concr. Res. 41(12) (2011) 1244-1256. https://doi.org/10.1016/j.cemconres.2010.12.001

[19] Saloma, A. Nasution, I. Imran, M. Abdullah, Improvement of concrete durability by $\begin{array}{lllll}\text { nanomaterials, } & \text { Procedia } & \text { Eng. } & 125 & \text { (2015) 608-612. }\end{array}$ https://doi.org/10.1016/j.proeng.2015.11.078

[20] F. Sanchez, K. Sobolev, Nanotechnology in concrete-a review, Constr. Build. Mater. 24(11) (2010) 2060-2071. https://doi.org/10.1016/j.conbuildmat.2010.03.014

[21] F. Pacheco-Torgal, S. Jalali, Nanotechnology: advantages and drawbacks in the field of construction and building materials, Constr. Build. Mater. 25(2) (2011) 582-590. https://doi.org/10.1016/j.conbuildmat.2010.07.009

[22] S. Ghazizadeh, P. Duffour, N.T. Skipper, Y. Bai, Understanding the behaviour of graphene oxide in Portland cement paste, Cem. Concr. Res. 111 (2018) 169-182. https://doi.org/10.1016/j.cemconres.2018.05.016

[23] D. Li, M.B. Muller, S. Gilje, R.B. Kaner, G.G. Wallace, Processable aqueous dispersions of graphene nanosheets, Nat. Nano. 3(2) (2008) 101-105. https://doi.org/10.1038/nnano.2007.451

[24] O.C. Compton, S.T. Nguyen, Graphene oxide, highly reduced graphene oxide, and graphene: versatile building blocks for carbon-based materials, Small 6(6) (2010) 711-723. https://doi.org/10.1002/smll.200901934

[25] L. Zhao, X. Guo, L. Song, Y. Song, G. Dai, J. Liu, An intensive review on the role of graphene oxide in cement-based materials, Constr. Build. Mater. 241 (2020) 117939. https://doi.org/10.1016/j.conbuildmat.2019.117939

[26] T.S. Qureshi, D.K. Panesar, B. Sidhureddy, A. Chen, P.C. Wood, Nano-cement composite with graphene oxide produced from epigenetic graphite deposit, Composites Part B: Engineering 159 (2019) 248-258. https://doi.org/10.1016/j.compositesb.2018.09.095

[27] M. Birenboim, R. Nadiv, A. Alatawna, M. Buzaglo, G. Schahar, J. Lee, G. Kim, A. Peled, O. Regev, Reinforcement and workability aspects of graphene-oxide-reinforced cement nanocomposites, Composites Part B: Engineering $161 \quad$ (2019) 68-76. https://doi.org/10.1016/j.compositesb.2018.10.030

[28] T.S. Qureshi, D.K. Panesar, Nano reinforced cement paste composite with functionalized graphene and pristine graphene nanoplatelets, Composites Part B: Engineering 197 (2020) 108063. https://doi.org/10.1016/j.compositesb.2020.108063

[29] T.S. Qureshi, D.K. Panesar, Impact of graphene oxide and highly reduced graphene oxide on cement based composites, Construction and Building Materials 206 (2019) 71-83. https://doi.org/10.1016/j.conbuildmat.2019.01.176

[30] A. Gholampour, M. Valizadeh Kiamahalleh, D.N.H. Tran, T. Ozbakkaloglu, D. Losic, From Graphene Oxide to Reduced Graphene Oxide: Impact on the Physiochemical and Mechanical Properties of Graphene-Cement Composites, ACS Applied Materials \& Interfaces 9(49) (2017) 43275-43286. http://doi.org/10.1021/acsami.7b16736

[31] W.S. Hummers, R.E. Offeman, Preparation of graphitic oxide, J. Am. Chem. Soc. 80(6) (1958) 1339-1339. https://doi.org/10.1021/ja01539a017

[32] S. Ghazizadeh, P. Duffour, N.T. Skipper, M. Billing, Y. Bai, An investigation into the colloidal stability of graphene oxide nano-layers in alite paste, Cem. Conc. Res. 99 (2017) 116128. https://doi.org/10.1016/j.cemconres.2017.05.011

[33] D.C. Marcano, D.V. Kosynkin, J.M. Berlin, A. Sinitskii, Z. Sun, A. Slesarev, L.B. Alemany, W. Lu, J.M. Tour, Improved synthesis of graphene oxide, ACS Nano 4(8) (2010) 4806-4814. https://doi.org/10.1021/nn1006368

[34] SS EN 197-1, Cement - Part 1: composition, specifications and conformity criteria for common cement, Singapore Standards Council, SPRING Singapore, 2014, p. 46 pages. https://www.nlb.gov.sg/biblio/201398199 
[35] ASTM C1702-15a, Standard test method for measurement of heat of hydration of hydraulic cementitious materials using isothermal conduction calorimetry, ASTM International, Pennsylvania, USA, 2015, p. 9 pages. https://doi.org/10.1520/C1702-15A [36] S. Ruan, J. Qiu, E.-H. Yang, C. Unluer, Fiber-reinforced reactive magnesia-based tensile strain-hardening composites, Cem. Concr. Res. $89 \quad$ (2018) 52-61. https://doi.org/10.1016/j.cemconcomp.2018.03.002

[37] M. Muthu, S. Kumar, E.H. Yang, C. Unluer, Degradation of carbonated reactive MgObased concrete exposed to nitric acid, J. $\mathrm{CO}_{2}$ Util. 36 (2020) 210-219. https://doi.org/10.1016/j.jcou.2019.11.006

[38] ASTM E384-17, Standard Test Method for Microindentation Hardness of Materials, ASTM International, Pennsylvania, USA, 2017. https://doi.org./10.1520/E0384-17

[39] Y. Dang, X. Shi, J. Qian, Y. Jiang, X. Li, Statistical Characteristics of Microhardness of Hardened Cement Paste, J. Wuhan Univ. Technol.-Mat. Sci. Edit. 33(4) (2018) 924-931. https://doi.org/10.1007/s11595-018-1914-9

[40] G. Xu, S. Du, J. He, X. Shi, The role of admixed graphene oxide in a cement hydration system, Carbon 148 (2019) 141-150. https://doi.org/10.1016/j.carbon.2019.03.072

[41] W.-J. Long, J.-J. Wei, F. Xing, K.H. Khayat, Enhanced dynamic mechanical properties of cement paste modified with graphene oxide nanosheets and its reinforcing mechanism, Cem. Concr. Compos. 93 (2018) 127-139. https://doi.org/10.1016/j.cemconcomp.2018.07.001

[42] H. Qin, W. Wei, Y. Hang Hu, Synergistic effect of graphene-oxide-doping and microwave-curing on mechanical strength of cement, J. Phys. Chem. Solids 103 (2017) 67-72. https://doi.org/10.1016/j.jpcs.2016.12.009

[43] H. Yang, M. Monasterio, H. Cui, N. Han, Experimental study of the effects of graphene oxide on microstructure and properties of cement paste composite, Compos. Part A Appl. Sci. Manuf. 102 (2017) 263-272. https://doi.org/10.1016/j.compositesa.2017.07.022

[44] Z. Lu, X. Li, A. Hanif, B. Chen, P. Parthasarathy, J. Yu, Z. Li, Early-age interaction mechanism between the graphene oxide and cement hydrates, Constr. Build. Mater. 152 (2017) 232-239. https://doi.org/10.1016/j.conbuildmat.2017.06.176

[45] E. Horszczaruk, E. Mijowska, R.J. Kalenczuk, M. Aleksandrzak, S. Mijowska, Nanocomposite of cement/graphene oxide - impact on hydration kinetics and Young's modulus, Constr. $\quad$ Build. Mater. 78 (2015) 234-242. https://doi.org/10.1016/j.conbuildmat.2014.12.009

[46] C. Lin, W. Wei, Y.H. Hu, Catalytic behavior of graphene oxide for cement hydration process, J. Phys. Chem. Solids 89 (2016) 128-133. https://doi.org/10.1016/j.jpcs.2015.11.002 [47] S.K.U. Rehman, Z. Ibrahim, M. Jameel, S.A. Memon, M.F. Javed, M. Aslam, K. Mehmood, S. Nazar, Assessment of rheological and piezoresistive properties of graphene based cement composites, Int. J. Concr. Struct. Mater. 12(1) (2018) 64. https://doi.org/10.1186/s40069-018-0293-0

[48] L. Zhang, D. Wang, W. Zhang, Multi-level flocculation structures of fresh cement paste by confocal laser scanning microscope, Journal of Wuhan University of Technology-Mater. Sci. Ed. 29(2) (2014) 302-308. https://doi.org/10.1007/s11595-014-0912-9

[49] M. Muthu, N. Ukrainczyk, E. Koenders, Effect of graphene oxide dosage on the deterioration properties of cement pastes exposed to an intense nitric acid environment, $\begin{array}{lllll}\text { Construction and Building } & \text { Materials }\end{array}$ https://doi.org/10.1016/j.conbuildmat.2020.121272

[50] P. Faucon, F. Adenot, J. Jacquinot, J. Petit, R. Cabrillac, M. Jorda, Long-term behaviour of cement pastes used for nuclear waste disposal: review of physico-chemical mechanisms of water degradation, Cem. Concr. Res. 28(6) (1998) 847-857. https://doi.org/10.1016/S0008$\underline{8846(98) 00053-2}$ 
[51] A. Hidalgo, S. Petit, C. Domingo, C. Alonso, C. Andrade, Microstructural characterization of leaching effects in cement pastes due to neutralisation of their alkaline nature: Part I: Portland cement pastes, Cem. Concr. Res. 37(1) (2007) 63-70. https://doi.org/10.1016/j.cemconres.2006.10.002

[52] H. Levin, W. Diamond, B. Brown, Influence of Ionic Strength on Ion Exchange, Industrial \& Engineering Chemistry 51 (1959) 313-318. https://doi.org/10.1021/IE51394A045

[53] H. Lajili, P. Devillers, C. Grambin-Lapeyre, J.P. Bournazel, Alteration of a cement matrix subjected to biolixiviation test, Materials and Structures 41(10) (2008) 1633-1645. https://doi.org/10.1617/s11527-008-9354-1

[54] W.-J. Long, T.H. Ye, Y.-C. Gu, H.-D. Li, F. Xing, Inhibited effect of graphene oxide on calcium leaching of cement pastes, Constr. Build. Mater. 202 (2019) 177-188. https://doi.org/10.1016/j.conbuildmat.2018.12.194

[55] R.E. Beddoe, H.W. Dorner, Modelling acid attack on concrete (Part I): the essential mechanisms, Cem. Concr. Res. 35(12) (2005) 2333-2339. https://doi.org/10.1016/j.cemconres.2005.04.002

[56] C.-J. Shih, S. Lin, R. Sharma, M.S. Strano, D. Blankschtein, Understanding the pHdependent behavior of graphene oxide aqueous solutions: a comparative experimental and molecular dynamics simulation study, Langmuir 28(1) (2011) 235-241. https://doi.org/10.1021/la203607w

[57] G.W. Scherer, Theory of drying, J. Am. Chem. Soc. 73(1) (1990) 3-14. https://doi.org/10.1111/j.1151-2916.1990.tb05082.x

[58] K. Scrivener, R. Snellings, B. Lothenbach, A practical guide to microstructural analysis of cementitious materials, Taylor \& Francis Group, Boca Raton, USA, 2016. https://doi.org/10.1201/b19074 